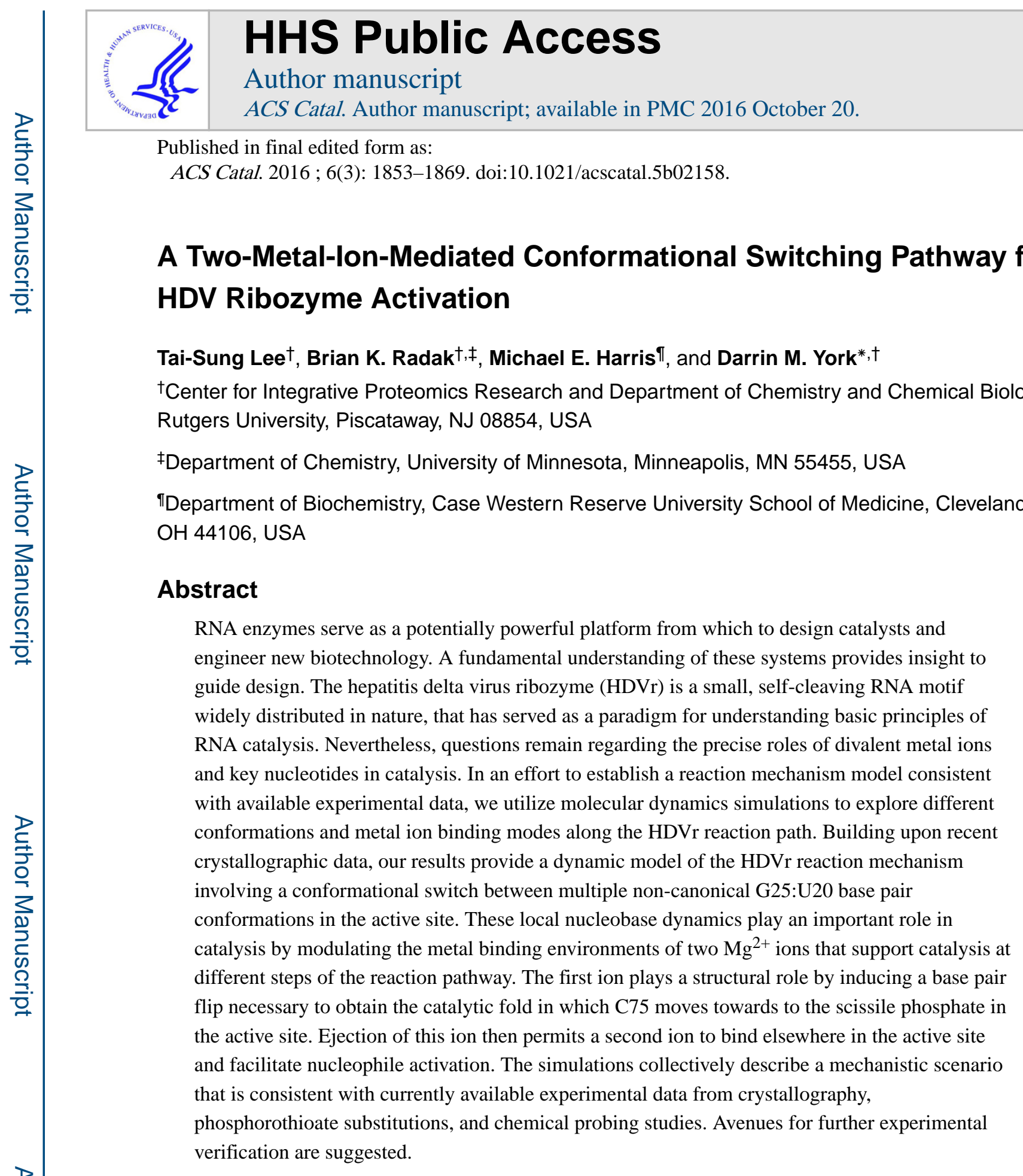

\title{
Introduction
}

Biological enzymes are among the most complex, selective and efficient known catalysts, and have seen increasing use in industrial applications compared to chemical catalysts. ${ }^{1,2}$ Proteins, with their diverse array of chemical functional groups, are extraordinarily

\footnotetext{
*To whom correspondence should be addressed Darrin.York@ rutgers.edu.

Supporting Information Available

Additional computational details. This material is available free of charge via the Internet at http://pubs.acs.org/.
} 
efficient, ${ }^{3}$ and for a long time, were thought to be the only biological catalysts. In the 1980s, however, it was discovered that RNA molecules could have catalytic activity, causing a veritable revolution in catalytic RNA research. ${ }^{4-8}$ RNA molecules have several assets as a platform for creating catalysts, and the engineering of new biotechnology based on catalytic RNAs is widespread, and ongoing. ${ }^{9}$ Nonetheless, it remains an open chemical question as to how RNA, with limited available nucleotide building blocks that are largely chemically inert, can fold so as to adopt three dimensional structures that are able to confer activity that rivals many protein enzymes. ${ }^{10,11}$ Consequently, it is an active area of catalytic research to understand the possible mechanistic strategies RNA can employ. Toward this end, the structural and kinetic characterization of the class of small nucleolytic RNA enzymes, or ribozymes, have been instrumental. ${ }^{12,13}$

The hepatitis delta virus ribozyme (HDVr), a small self-cleaving catalytic RNA motif, is a prototype nucleolytic ribozyme that catalyzes RNA 2'-O-transphosphorylation which involves an inline nucleophilic attack by $\mathrm{U}-1: \mathrm{O}_{2}$, on the adjacent scissile phosphate, and cleavage of the $\mathrm{P}-\mathrm{O}_{5}$, bond of $\mathrm{G} 1$ to produce a 2',3'-cyclic phosphate and a 5' hydroxyterminus. Originally found as a satellite of the hepatitis B virus where it plays a role in the viral life cycle, ${ }^{14-17} \mathrm{HDV}$-like ribozyme sequences have subsequently been found in other prokaryotic and eukaryotic genomes (including that of humans). ${ }^{18,19}$ The motif may be an important tool in as yet unrealized biological roles. ${ }^{20-23}$ Extensive structural and biochemical evidence supports a mechanism involving general acid and metal ion catalytic modes. ${ }^{24,25}$ However, there is still no strong consensus on the exact role(s) of divalent metal ions in transition state stabilization nor the specific conformations required at different stages of the reaction. ${ }^{25,26}$

The first crystal structure of HDVr was reported in the cleaved (i.e. product) form ${ }^{27}$ with an overall fold consistent with mutagenesis and chemical probing studies of the solution conformation. ${ }^{28,29}$ In that structure, $\mathrm{C} 75: \mathrm{N}_{3}$ is in a position to form a hydrogen bond with $\mathrm{G} 1: \mathrm{O}_{5}$, (the leaving group) suggesting that $\mathrm{C} 75$ acts as a general acid to stabilize the leaving group. ${ }^{30,31}$ This hypothesis is supported by inactivation of the ribozyme by C75 mutation as well as other experimental approaches. ${ }^{30,32-36}$ In particular, pre-activation of the leaving group by phosphorothioate substitution renders the ribozyme insensitive to C75 mutation. ${ }^{31}$

Consistent with its role in acid catalysis, the protonation state of C75 is also critically important. It has been well established that the $\mathrm{p} K_{\mathrm{a}}$ of $\mathrm{C} 75$ is shifted towards neutrality in order to act optimally as a general acid. ${ }^{30,33,34,36-38}$ Nevertheless, the interactions that influence the protonation state of $\mathrm{C} 75$ along the reaction coordinate have not been resolved. Raman crystallography experiments reported that the $\mathrm{p} K_{\mathrm{a}}$ of $\mathrm{C} 75$ is shifted to around 6.1-6.4 in the presence of different deactivated nucleophiles, ${ }^{35}$ while NMR experiments have shown that the $\mathrm{p} K_{\mathrm{a}}$ of $\mathrm{C} 75$ is not shifted significantly in the product and the reactant states compared to solution ( $\left.\mathrm{p} K_{\mathrm{a}} \simeq 4.5\right) .{ }^{37}$ As such, it is desirable to explore the interactions between $\mathrm{C} 75$ and its neighboring residues at different stages of the reaction, especially as a function of protonation/deprotonation. Indeed, it has been suggested that C75 might be properly positioned for reaction only after the precursor is formed, ${ }^{39}$ which was interpreted as supporting the role of protonated C75 as the general acid, but only near the transition 
state. Recently the protonation state of $\mathrm{C} 75$ has also been suggested to play a critical role in forming the inline conformation. ${ }^{40}$

Until recently, the crystallographic data from HDV ribozymes that have been inactivated by a C75U mutant was interpreted such that G25 and U20 form a weak trans Watson-Crick/ Hoogsteen (tWH) base pair (Figure 2); 41 a divalent ion was also resolved bound to $\mathrm{U} 75: \mathrm{O}_{4} \cdot{ }^{42,43}$ However, in structures of the cleaved product, ${ }^{28,29}$ as well as a recently reported pre-cleavage structure, ${ }^{44} \mathrm{G} 25$ and $\mathrm{U} 20$ are resolved as a "reverse wobble" pair (trans Watson-Crick/Watson-Crick, tWW) where $\mathrm{G} 25: \mathrm{N}_{7}$ and $\mathrm{G} 25: \mathrm{O}_{6}$ may provide a preferred environment for $\mathrm{Mg}^{2+}$ binding (Figure 2) ${ }^{45,46}$ Conversely, in a structure where divalent ions had been removed, the position of the G25 ribose is not resolved and the nearby $\mathrm{C} 24$ is not stacked on G25. ${ }^{42}$ Recently, a C75U pre-cleavage structure as well as a post-cleavage structure were refined with new computational tools. ${ }^{47}$ In these newly fitted structures G25 and U20 are also resolved in the "reverse wobble" (tWW) conformation. Finally, the L3 loop of HDVr (where the G25:U20 base pair is located) is believed to be highly flexible ${ }^{48}$ and prone to misfolding. ${ }^{49}$ Its conformation may also be metal iondependent ${ }^{50,51}$ and chemical modification results suggest that $\mathrm{G} 25$ may be exposed to solvent during the course of the reaction. ${ }^{52}$ Although the pair conformation may be flexible, both G25 and U20 are completely conserved across different species, implying they are critical for the reaction. ${ }^{19}$

Regarding the active conformation, based on experimentally observed stereochemical inversion of the phosphorus center ${ }^{53-55}$ lack of isomerization (RNA migration) products, it is generally accepted that small ribozymes require inline conformations to facilitate the $\mathrm{S}_{N^{2}}$ like mechanism of cleavage, ${ }^{53-56}$ although the possibility of an alternative mechanism involving pseudorotation cannot be definitively ruled out. ${ }^{57}$ Nevertheless, the inline conformation necessary for the HDVr reaction has never been observed in any reported crystal structure to date. Indeed, in the pre-cleavage structures of the HDVr the inline attacking angles are less than 90 degrees. ${ }^{42,44}$ Although it has been suggested that there may be some space for $\mathrm{U}-1$ to undergo a rigid rotation to reach the necessary orientation, ${ }^{42}$ such a rotation has not yet been directly tested experimentally. ${ }^{24} \mathrm{~A}$ recently reported pre-cleavage structure shows U-1 to be unresolved and hence does not provide direct structural evidence for an inline conformation, although it has been suggested that the HDVr inline conformation could be modeled based on an active Hammerhead ribozyme structure. ${ }^{44,58}$ Our previous simulations revealed a spontaneous rotation of U-1 that led to an inline conformation, apparently driven by deprotonation of $\mathrm{U}-1: \mathrm{O} 2,{ }^{59}$

Although significant constraints have been established, no clear "best" representative picture of the active site nor the reaction path has yet emerged. Indeed, experimental observations seem to strongly suggest that the reaction is highly coupled with conformational switching events and metal ion binding modes. ${ }^{39,40,42,60}$ As such, a key position in this work (and one not without precedent ${ }^{39,60}$ ) is that a single, static conformational description of the $\mathrm{HDVr}$ active site is insufficient to capture the complete mechanism.

A related unanswered question is the role(s) of the metal ion(s) in the HDVr reaction. Although not absolutely required for catalysis, the presence of divalent metal ions at 
millimolar levels significantly enhances the HDVr reactivity. ${ }^{16,28,61-63}$ There is vast experimental data regarding the active site $\mathrm{Mg}^{2+}$ and it is believed that there is at least one hydrated $\mathrm{Mg}^{2+}$ ion near the active site. ${ }^{26,30,42,64}$ Some data have been interpreted as indicating two $\mathrm{Mg}^{2+}$ ions in the active site $23,43,65,65,66$ and it has been suggested that the active site $\mathrm{Mg}^{2+}$ ion(s) may play two types of roles. ${ }^{25,32,66,67}$ The first is structural; the $\mathrm{Mg}^{2+}$ ion binding facilitates the formation of the active conformation. ${ }^{32}$ The second is chemical, an $\mathrm{Mg}^{2+}$ bound hydroxide acts as a base extracting to activate the 2 ' $\mathrm{OH}$ group of $\mathrm{U}-1,30,32,68$ or $\mathrm{Mg}^{2+}$ could act in a Lewis acid role to lower the $\mathrm{p} K_{\mathrm{a}}$ of the $\mathrm{O} 2$ ' nucleophile. ${ }^{44,66}$ Nevertheless, most recent mechanistic models have focused heavily on "the catalytically critical divalent metal ion".36,42,46,65,66,68-72

Furthermore, it has been shown that $\mathrm{Co}\left(\mathrm{NH}_{3}\right)_{6}^{3+}$ (which can compete with $\mathrm{Mg}^{2+}$ in binding but cannot form inner sphere coordination interactions) inhibits HDVr activity. ${ }^{30,70}$ The active site $\mathrm{Mg}^{2+}$ ion has been shown to directly interact with critical active site residues ${ }^{65,73}$ and modification of the linkage at the scissile phosphate can alter metal ion preference. ${ }^{62,74}$ A recent crystal structure of the HDVr in the pre-cleavage state(using a deoxy substrate), combined with molecular modeling, lead to the hypothesis that the $\mathrm{Mg}^{2+}$ directly coordinates $\mathrm{U}-1: \mathrm{O} 2$ ' as well as the G1:pro- $\mathrm{R}_{\mathrm{P}}$ oxygen. ${ }^{44}$ Thio-substitution of the pro- $\mathrm{R}_{\mathrm{P}}$ oxygen of the scissile phosphate has been utilized to explore possible direct $\mathrm{Mg}^{2+}$ binding, but no direct rescue effect from $\mathrm{Mn}^{2+}$ was observed. ${ }^{75,76}$ However, in recent studies an $\mathrm{Rp}$ thio substitution was observed to result in two slow reaction phases, and an "unconventional" rescue of the Rp thio effect was observed in which the rescuing ion, $\mathrm{Cd}^{2+}$, inhibits the wild-type but not the pro- $\mathrm{R}_{\mathrm{P}}$ thio-substituted ribozyme. ${ }^{71,72}$ Large pro- $\mathrm{R}_{\mathrm{P}}$ thio effects are also observed in reactions with monovalent ions alone, however, the thio effects at the pro-S $\mathrm{S}_{\mathrm{P}}$ position result in faster reaction rates (termed inverse thio effects). The $\mathrm{pH}$ profiles are very different: bell-shaped profiles are found with native $\mathrm{Mg}^{2+}$ and other small divalent ions, ${ }^{23,72}$ but are inverted with large divalent ions or monovalent ions. ${ }^{30,32,36,72,77}$ Additionally, a proton inventory of one is observed in monovalent ions while an invetory of two is observed for reactions containing $\mathrm{Mg}^{2+}$ consistent with participation of a metal hydrate in catalysis. ${ }^{78}$

Although detailed models of the roles of metals in HDV mechanism have been proposed based on extensive biochemical data, important ambiguities remain. A consistent description of the HDVr catalytic mechanism thus appears to be precluded by 1.) various conformations of the active site (Figure 1) in the available structures and 2.) different proposals regarding the role of the active site $\mathrm{Mg}^{2+}$. Similar ambiguities are inherent in many ribozymes and protein metallophosphoryltransferases. A recent simulation work suggests that crystal structures may represent trapped intermediates along the reaction coordinate. ${ }^{40}$ Long time molecular dynamics simulation can serve as a powerful tool complementing experimental observations to establish a hypothesis that consolidates all available empirical evidence. ${ }^{40,59,66,79-83}$ Recent QM/MM simulations ${ }^{68,71,72,82,84}$ starting from a proposed starting structural model of the active site ${ }^{44}$ have delivered a detailed, even quantitative, picture of several reaction pathways in the HDVr. However, at the same time, these QM/MM simulations fail to explain most qualitative observations, e.g., the comparison of reaction barriers in the presence and absence of $\mathrm{Mg}^{2+} .{ }^{24}$ In order to explore additional plausible 
scenarios of the HDVr reaction, here we significantly extend the scope of past simulation studies to include various starting conformations, $\mathrm{C} 75$ protonation states, and $\mathrm{Mg}^{2+}$ binding modes at different stages of the HDVr reaction. The results inspire a novel, dynamic view of the HDVr reaction where conformational events (especially changes in G25:U20 base pairing), metal ion binding modes, the $\mathrm{C} 75$ protonation state, and chemical steps are all highly coupled.

\section{Simulation Setup}

This work greatly extends the scope of our previous simulations ${ }^{59}$ with a consistent protocol. The extension of this work is briefly described below. Detailed description of the simulation setup and protocols can be found in the Supporting Information. The Amber ${ }^{85,86}$ parm99 force field with the $a / \gamma$ corrections for nucleic acids, which has been demonstrated to significantly improve nucleic acid side chain conformations, ${ }^{87}$ was employed. The parameters of $\mathrm{Mg}^{2+}$ specifically optimized for RNA binding were utilized. ${ }^{88}$ In the present study, the purpose is to identify plausible catalytically active states (i.e., conformations, metal ion binding modes and protonation states) along the reaction coordinate that can be used as a departure point for further investigation of the chemical steps of the reaction with more sophisticated QM/MM models.

More than thirty long time ( $\geq 300 \mathrm{~ns}$ each and roughly $10 \mu \mathrm{s}$ in total) molecular dynamics simulations at different stages along the HDVr reaction coordinate were performed with different starting conditions: the G25:U20 base pair in either its tWW or tWH forms ${ }^{41}$ (Figure 2), $\mathrm{C} 75$ protonated or neutral, and $\mathrm{Mg}^{2+}$ ion(s) at different binding modes.

\section{$\mathrm{Mg}^{2+}$ binding sites}

It has been suggested that there are two possible $\mathrm{Mg}^{2+}$ binding sites, one near G1: $\mathrm{N}_{7} 43,58,65,70,89$ and another near the active site phosphate (possibly bound to $\mathrm{U} 75: \mathrm{O}_{6}$ in the case of C75U mutants) $)^{43}$ or near G25: $\mathrm{N}_{7}$ in other structures. ${ }^{43,46,81}$ In accordance with the previously reported notation, ${ }^{43}$ the binding site near $\mathrm{G} 1: \mathrm{N}_{7}$ is defined as the "C-site" and the site near $\mathrm{U} 75: \mathrm{O}_{6} / \mathrm{G} 25: \mathrm{N}_{7}$ as the "B-site". In all simulations reported here, the B-site initial position was either taken directly from the crystal structure (PDB: 1VC7) when G25:U20 was in the tWH form or modeled by placing a $\mathrm{Mg}^{2+}$ ion $4.0 \AA$ from $\mathrm{G} 25: \mathrm{N}_{7}$ when G25:U20 was in its reverse wobble form. The C-site initial position was at $2.0 \AA$ from $\mathrm{G} 1: \mathrm{N}_{7}$, as suggested in other work. ${ }^{43,65}$

\section{G25:U20 base pairing modes}

There are two types of G25:U20 base pair conformations in the reported crystal structures (Figure 2): trans Watson-Crick/Hoogsteen (tWH) ${ }^{42,43}$ and the unusual trans Watson-Crick/ Watson-Crick wobble ( $\mathrm{tWW}$, also referred to as a reverse wobble). ${ }^{28,29,44,47,47}$ In order to explore these two possible G25:U20 base pairings, initial structures with different G25:U20 conformations were used. The initial starting positions of all other residues were the same as in our previous work, ${ }^{59}$ which was derived from a C75U crystal structure (1VC7). To our knowledge, there is no fully resolved U-1 residue in any reported structure with G25:U20 in the tWW form. Hence, the following procedure was taken to build the initial structures with 
G25:U20 in the tWW form. After $10 \mathrm{~ns}$ of solvent and ion equilibration, the structures with G25:U20 in the tWH form were modiffed by rotating the $\mathrm{G} 25$ glycosidic bond torsion $\left(\mathrm{O}^{4^{\prime}}\right.$ -

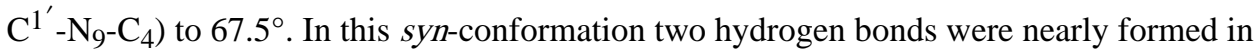
the expected tWW pattern $\left(\mathrm{G} 25: \mathrm{N}_{1}-\mathrm{U} 20: \mathrm{O}_{4}\right.$ and $\left.\mathrm{G} 25: \mathrm{O}_{6}-\mathrm{U} 20: \mathrm{N}_{3}\right)$. This was followed by an additional $1 \mathrm{~ns}$ equilibration of solvent and ions. The resulting structures underwent further relaxation with two hydrogen bonds $\left(\mathrm{G} 25: \mathrm{N}_{1}-\mathrm{U} 20: \mathrm{O}_{4}\right.$ and $\left.\mathrm{G} 25: \mathrm{O}_{6}-\mathrm{U} 20: \mathrm{N}_{3}\right)$ restrained with $20 \mathrm{kcal} / \mathrm{mol}-\AA^{2}$ harmonic potentials for $10 \mathrm{~ns}$ to ensure the proper response and relaxation of the surrounding residues. The final structures then served as the starting structures for the reported MD simulations.

\section{C75 protonation states and stages along the reaction coordinate}

Both C75 in its neutral and protonated forms were used in the simulations as reported previously. ${ }^{59}$ In addition, simulations were performed at different stages of the reaction: reactant state, activated precursor state, early transition state mimic, late transition state mimic, and product state.

\section{Simulations performed}

We use the following notations for $\mathrm{Mg}^{2+}$ binding sites: $\mathrm{M}_{B}$ stands for a $\mathrm{Mg}^{2+}$ placed at the B-site initially and $\mathrm{M}_{C}$ at the $\mathrm{C}$-site. For G25:U20 base pairing modes, "tWH" stands for initial structures in the tWH pair form and "tWW" in the tWW (reverse wobble) form. For $\mathrm{C} 75$ protonation states, $\mathrm{C} 75^{0}$ stands for neutral $\mathrm{C} 75$ while $\mathrm{C} 75^{+}$for protonated $\mathrm{C} 75$.

Different stages of the reaction are marked as: reactant state (RT), activated precursor state (dRT), early transition state mimic (ETS), late transition state mimic (LTS), and product state (PD). All simulations are listed in the tables in the Results Section.

\section{Results and Discussion}

\section{The B-site $\mathrm{Mg}^{2+}$ ion stabilizes the tWW conformation and brings $\mathrm{C} 75$ close to the scissile phosphate, resulting in a downshift of the $\mathrm{C} 75 \mathrm{pKa}$}

Table 1 lists key geometric parameters characterizing the base pairing of G25:U20, the $\mathrm{Mg}^{2+}$ binding of the $\mathrm{B}$ - and $\mathrm{C}$-sites, and the position of $\mathrm{C} 75$ in reactant state simulations under various conditions. The glycosidic bond torsion angle, $\chi$, of G25 is an indicator of the syn/ anti conformation of $\mathrm{G} 25$. Distances from $\mathrm{C} 75: \mathrm{N}_{3}$ to both $\mathrm{G} 1: \mathrm{O}_{1 P}$ and $\mathrm{G} 1: \mathrm{O}_{2} P$ were calculated and the average of their reciprocal values are shown as a measure of the electrostatic interaction $\left(\left\langle\frac{1}{r_{1}}+\frac{1}{r_{2}}\right\rangle\right.$ in all tables). Such average values can be used to rationalize the possible positive $\mathrm{p} K_{\mathrm{a}}$ shift of $\mathrm{C} 75: \mathrm{N}_{3}$.

In the tWW_RT_C75 ${ }^{0} \mathrm{M}_{B}$ simulation, G25:U20 was initially in a tWW conformation and $\mathrm{Mg}^{2+}$ was placed at the B-site with an outer sphere coordination at G25: $\mathrm{N}_{7}$. The G25:U20 tWW conformation is stable throughout the simulation (total $250 \mathrm{ns)}$ ) as indicated by the strong hydrogen bonds between $\mathrm{G} 25: \mathrm{N}_{1} / \mathrm{U} 20: \mathrm{O}_{6}$ and $\mathrm{U} 20: \mathrm{N}_{3} / \mathrm{G} 25: \mathrm{O}_{6}$. G25 remained in a syn conformation $\left(\chi=75.5^{\circ}\right)$ and the $\mathrm{Mg}^{2+}$ kept its initial binding mode to $\mathrm{G} 25: \mathrm{N}_{7}$ with an average distance of $4.90 \AA$. 
In the tWW_RT_C75 ${ }^{0} \mathrm{M}_{C}$ simulation, $\mathrm{Mg}^{2+}$ was initially placed at the $\mathrm{C}$-site where it coordinated with G1: $\mathrm{N}_{1}$. The $\mathrm{Mg}^{2+}$ did not maintain its coordination with $\mathrm{G} 1: \mathrm{N}_{1}$ and was eventually (after $\sim 100 \mathrm{~ns}$ ) ejected from the C-site (average distance $=7.41 \AA$ ). Interestingly, the G25:U20 tWW conformation, although it was stable for most of the simulation, was weakened, as indicated by the fact that the two key hydrogen bonds, G25: $\mathrm{N}_{1} / \mathrm{U} 20: \mathrm{O}_{6}$ and $\mathrm{U} 20: \mathrm{N}_{3} / \mathrm{G} 25: \mathrm{O}_{6}$, were maintained in only $60 \%$ of the snapshots (see the criteria in Table 1 ), down from around $80 \%$ in the tWW_RT_C75 ${ }^{0} \mathrm{M}_{B}$ simulation. G25 showed strong deviation in its $\chi$ angle and switched towards an anti conformation after $\mathrm{Mg}^{2+}$ left the $\mathrm{C}$-site (average $\left.\chi=151.4^{\circ}\right)$. The tWW_RT_C75 ${ }^{0} \mathrm{M}_{C}$ simulation thereafter essentially became identical to the tWW_RT_C75 ${ }^{0}$ simulation discussed below.

In the tWW_RT_C75 ${ }^{0}$ simulation, no $\mathrm{Mg}^{2+}$ ion was placed at either the B-site or C-site. Although the overall active site integrity is more or less maintained, the G25:U20 tWW conformation is significantly weakened as indicated by the two key hydrogen bonds (G25: $\mathrm{N}_{1} / \mathrm{U} 20: \mathrm{O}_{6}$ and $\mathrm{U} 20: \mathrm{N}_{3} / \mathrm{G} 25: \mathrm{O}_{6}$ ) being present only $20 \%$ of the time. In addition, the loss of these hydrogen bonding interactions correlates with rotation of G25 towards anti conformation (average $\chi=-169.2^{\circ}$ ). A similar tWW_RT_C7 $75^{0}$ simulation (labeled as tWW_RT_C75 ${ }^{0}$ fix in Table 1) was performed in which two key hydrogen bonds, G25: $\mathrm{N}_{1}$ / $\mathrm{U} 20: \mathrm{O}_{6}$ and $\mathrm{U} 20: \mathrm{N}_{3} / \mathrm{G} 25: \mathrm{O}_{6}$, were restrained throughout the simulation. Despite enforcing the tWW pairing, G25 appeared to prefer an anti conformation (average $\chi=-167.1^{\circ}$ ).

Another independent $300 \mathrm{~ns}$ simulation was performed and delivered qualitatively the same results (see Table S1).

The above simulation results of tWW_RT_C75 ${ }^{0}$ with different initial binding modes of $\mathrm{Mg}^{2+}$ suggest that the B-site $\mathrm{Mg}^{2+}$ is critical for maintaining the syn gylcosidic torsion and hence the tWW (reverse wobble) conformation, likely through water-mediated coordination at G25: $\mathrm{N}_{7}$. The G25 base prefers an anti conformation even when a tWW base pair is enforced (tWW_RT_C75 ${ }^{0}$ fix). This is consistent with crystallographic evidence ${ }^{44}$ and chemical probing experiments. ${ }^{45}$

Another set of simulations were performed with G25:U20 initially in the tWH conformation, again with various initial binding modes of $\mathrm{Mg}^{2+}$. In all simulations the tWH conformation was not stable, as indicated by the necessary hydrogen bonds weakening until essentially no base pair interaction was present. The tWH conformation is therefore not stable in the reactant state, regardless of the $\mathrm{Mg}^{2+}$ binding mode. This observation is consistent with the fact that the G25 position was not resolved and is likely flexible in the crystal without $\mathrm{Mg}^{2+}$ ions. ${ }^{42}$ When $\mathrm{Mg}^{2+}$ was initially placed at the B-site (tWH_RT_C $75^{0} \mathrm{M}_{B}$ ) it quickly coordinated directly with $\mathrm{G} 1: \mathrm{O}_{2 P}$ (average distance $1.87 \AA$ ). When $\mathrm{Mg}^{2+}$ was initially placed at the C-site (tWH_RT_C75 $\left.{ }^{0} \mathrm{M}_{C}\right)$ it maintained its inner sphere coordination with $\mathrm{G} 1: \mathrm{N}_{7}$ for the first $100 \mathrm{~ns}$ and then moved to outer sphere coordination (average distance $5.62 \AA$ ). In all tWH simulations, G25 kept an anti conformation (average $\chi$ between $-50^{\circ}$ and $-80^{\circ}$ ).

The $\left\langle\frac{1}{r_{1}}+\frac{1}{r_{2}}\right\rangle$ term in Table 1 can be treated as a measure of the electrostatic effect on C75: $\mathrm{N}_{3}$ from $\mathrm{G} 1: \mathrm{O}_{1 P}$ and $\mathrm{G} 2: \mathrm{O}_{1 P}$. Here, in all simulations of the reactant state in the tWW 
conformation, these values are almost identical, indicating that in the tWW conformation $\mathrm{C} 75$ positions itself independently of the $\mathrm{Mg}^{2+}$ binding mode. The only exception is when $\mathrm{Mg}^{2+}$ is absent, in which case the value is slightly higher and $\mathrm{G} 1: \mathrm{O}_{1 P} / \mathrm{G} 2: \mathrm{O}_{1 P}$ are enforced to be in tWW conformation (tWW_RT_C75 _fix, $\left\langle\frac{1}{r_{1}}+\frac{1}{r_{2}}\right\rangle=0.46$ ). Nevertheless, in tWH simulations the $\left\langle\frac{1}{r_{1}}+\frac{1}{r_{2}}\right\rangle$ value becomes much smaller when the $\mathrm{Mg}^{2+}$ is initially placed at B-site (tWH_RT_C75 ${ }^{0} \mathrm{M}_{B},\left\langle\frac{1}{r_{1}}+\frac{1}{r_{2}}\right\rangle$ or when $\mathrm{Mg}^{2+}$ is absent from both sites (tWH_RT_C75,$\left\langle\frac{1}{r_{1}}+\frac{1}{r_{2}}\right\rangle=0.31$ ). Although the value is much higher when $\mathrm{Mg}^{2+}$ is initially placed at the C-site (tWH_RT_C75 ${ }^{0} \mathrm{M}_{C},\left\langle\frac{1}{r_{1}}+\frac{1}{r_{2}}\right\rangle=0.49$ ), this could be a simulation artifact, as this $\mathrm{Mg}^{2+}$ gradually dissociate from the $\mathrm{C}$-site and the system is likely to eventually behave in the same way as the tWH_RT_C75 $5^{0}$ case after the $\mathrm{Mg}^{2+}$ is no longer bound.

All of the simulation results of the reactant state mentioned here imply that: a) The tWH conformation is unstable in the reactant state, regardless of the $\mathrm{Mg}^{2+}$ binding mode. $b$ ) The tWW (reverse wobble) pair is stable in the reactant state with $\mathrm{C} 75: \mathrm{N}_{3}$ close proximal to $\mathrm{G} 1: \mathrm{O}_{1 P}$ and $\mathrm{G} 2: \mathrm{O}_{1 P}$; this juxtaposition is apparently induced by $\mathrm{Mg}^{2+}$ binding at the $\mathrm{B}$-site. c) The tWH base pairing may not be able to position $\mathrm{C} 75: \mathrm{N}_{3}$ close to $\mathrm{G} 1: \mathrm{O}_{1 P}$ and G2: $\mathrm{O}_{1 P}$

A possible mechanistic pathway that draws together these simulations, shown in Figure 3, is as follows. In the reactant state, a tWH pair is more stable than a tWW pair if there is no $\mathrm{Mg}^{2+}$ bound near the active site. With $\mathrm{Mg}^{2+}$ at the $\mathrm{B}$-site, a tWW pair is preferred and leads to a re-positioning of $\mathrm{C} 75: \mathrm{N} 3$ such that it is proximal to $\mathrm{G} 1: \mathrm{O}_{1}$ and $\mathrm{G} 2: \mathrm{O}_{1}$, thereby increasing its $\mathrm{p} K_{\mathrm{a}}$. Note that here it is the conformation that leads to the $\mathrm{p} K_{\mathrm{a}}$ shift, not the $\mathrm{Mg}^{2+}$ ion. In fact, in the tWW conformation the B-site $\mathrm{Mg}^{2+}$ will likely shift the $\mathrm{p} K_{\mathrm{a}}$ of $\mathrm{C} 75$ downward, not upward, due to Coulombic repulsion.

Hence, the B-site $\mathrm{Mg}^{2+}$ plays a structural role resulting in a conformation favorable for the $\mathrm{p} K_{\mathrm{a}}$ shift of $\mathrm{C} 75$. This scenario is consistent with the second reaction channel model proposed by Nakano et al. ${ }^{90}$ in which the contribution of a structural metal ion was deduced from kinetic experiments. Moreover, this model explains the discrepancy that C75 is observed without a significant $\mathrm{p} K_{\mathrm{a}}$ shift using $\mathrm{NMR}^{37}$ but shows a $\sim 2.0$ unit shift using Raman crystallography, as well as a slight anti-correlation with the $\mathrm{Mg}^{2+}$ concentration. ${ }^{35}$ The HDVr could be trapped in the tWW conformation in the Raman crystallography experiments but in an equilibrium between tWW/tWH conformations under solution conditions.

\section{Protonation of $\mathrm{C} 75$ leads to stabilization of the $\mathrm{tWH} / \mathrm{cWW}$ conformations that favor binding of a $\mathrm{Mg}^{2+}$ at the $\mathrm{C}$-site, where the $\mathrm{Mg}^{2+}$ ion may act as the base catalyst through a coordinating water}

There is abundant experimental and theoretical evidence that protonation of C75 is a prerequisite for the HDVr reaction. Nevertheless, this change in the $\mathrm{C} 75$ charge state will 
necessarily cause a non-trivial electrostatic perturbation and the active site environment will respond accordingly. Hence, it is necessary to identify possible conformational changes and $\mathrm{Mg}^{2+}$ binding modes that are sensitive to the protonated C75. Similar to Table 1, Table 2 lists key geometric parameters characterizing the base pairing of G25:U20 and the $\mathrm{Mg}^{2+}$ binding of the B and C-sites, but now in the presence of protonated $\mathrm{C} 75$.

In the tWW_RT_C75 ${ }^{+} \mathrm{M}_{B}$ simulation, $\mathrm{Mg}^{2+}$ remains at the B-site, but the tWW conformation is clearly weakened, although G25 retains its syn conformation (average $\left.\chi=65.5^{\circ}\right)$. It is clear that once $\mathrm{C} 75$ is protonated, the $\mathrm{B}$-site $\mathrm{Mg}^{2+}$ no longer prefers coordination with $\mathrm{G} 25: \mathrm{N}_{7}$ (average distance $6.03 \AA$ ) and, during the simulation it never gets close enough to the nucleophile (U-1: $\mathrm{O}^{2}$ ) to possibly act as a base catalyst (average distance $7.83 \AA$ ).

The two characteristic hydrogen bonds of the tWW conformations are essentially lost in the tWW_RT_C75 ${ }^{+} \mathrm{M}_{B}$ simulation. Hence the tWW form is not stable after $\mathrm{C} 75$ is protonated. This apparently results from electrostatic repulsion between the B-site $\mathrm{Mg}^{2+}$ and $\mathrm{C}^{2} 5^{+}$, which pushes the B-site $\mathrm{Mg}^{2+}$ away from the active site (II' in Figure 4). Thus the simulation results so far suggest that the $\mathrm{B}$-site $\mathrm{Mg}^{2+}$ creates an environment that increases the probability of $\mathrm{C} 75$ protonation, i.e., increases its $\mathrm{p} K_{\mathrm{a}}$. However, once $\mathrm{C} 75$ is protonated the metal ion loses its binding to $\mathrm{G} 25: \mathrm{N}_{7}$ and which favors dissociation from the active site (see below).

In the tWW_RT_C75 ${ }^{+} \mathrm{M}_{C}$ simulation, $\mathrm{Mg}^{2+}$ remains at the $\mathrm{C}$-site and again the tWW hydrogen bonds are lost. However, now G25 rotates towards an anti conformation (average $\chi=120.7^{\circ}$ ) after $170 \mathrm{~ns}$ (switching from $\sim-50^{\circ}$ to $\sim 180^{\circ}$ then to $\sim 275^{\circ}$, Figure 5) and the tWW conformation is lost, potentially on its way to reach a tWH or cWW geometry. The $\mathrm{Mg}^{2+}$ steadily coordinates to the nucleophile through a water molecule and is poised to act as the base catalyst (average distance $4.09 \AA$ ).

We further investigated the relationship between C-site $\mathrm{Mg}^{2+}$ binding and the G25:U20 tWW conformation in an additional tWW_RT_C75 ${ }^{+} \mathrm{M}_{C}$ simulation (denoted as tWW_RT_C75 ${ }^{+} \mathrm{M}_{C \_}$fix) in which harmonic biasing potentials were applied to enforce the hydrogen bonds between the bases. The results, listed in Table 2, show that the $\mathrm{C}$-site $\mathrm{Mg}^{2+}$ still remains at the $\mathrm{C}$-site during the simulation (average distance $2.23 \AA$ ) but no longer coordinates to the nucleophile, $\mathrm{U}-1: \mathrm{O}^{2}$ (average distance $8.14 \AA$ ). The observation that the $\mathrm{B}$-site $\mathrm{Mg}^{2+}$ cannot stay with the tWW conformation, was veriffed by another independent $300 \mathrm{~ns}$, tWW_RT_C75 ${ }^{+} \mathrm{M}_{2}$, simulation where two $\mathrm{Mg}^{2+}$ ions were added at both B- and Csite initially (Table $\mathrm{S} 2$ ).

After closely examining the conformational differences between tWW_RT_C75 ${ }^{+} \mathrm{M}_{C}$ and tWW_RT_C75 ${ }^{+} \mathrm{M}_{C}$ fix, we find that when G25:U20 is enforced in a tWW (reverse wobble) conformation, $\mathrm{G} 25: \mathrm{N}_{7}$ favors the binding of sodium ions in the active site to form a relatively rigid network of interactions with nearby residues. Conversely, when a $\mathrm{Mg}^{2+}$ is present at the $\mathrm{C}$-site, the binding of sodium ions in the active site will be unfavorable due simple electrostatic repulsion. The result is that, with $\mathrm{C}$-site $\mathrm{Mg}^{2+}$ binding, the conformational preference of G25:U20 is shifted from tWW to tWH/cWW. This observation 
is also supported by the tWW_RT_C75 ${ }^{+}$simulation where no $\mathrm{Mg}^{2+}$ is in either site: The tWW conformation is kept during the whole simulation time (300 ns), as strongly as in the simulations with biasing potentials (tWW_RT_C75 ${ }^{+} \mathrm{M}_{C}$ fix).

Another set of simulations were performed with C75 protonated but G25:U20 initially in its tWH conformation and $\mathrm{Mg}^{2+}$ alternately placed at the B-site, C-site, or $\mathrm{Mg}^{2+}$ absent. The results suggest (Table 2) that binding of the B-site $\mathrm{Mg}^{2+}$ would destabilize the G25:U20 base interaction as all hydrogen bonds are lost, which is further veriffed by a repeated simulation (Table S2). Nevertheless, the tWH conformation is somehow kept with some distribution of the cWW conformation in both simulations with C-site $\mathrm{Mg}^{2+}$ or no $\mathrm{Mg}^{2+}$. The $\mathrm{Mg}^{2+}$ in tWH_RT_C75 ${ }^{+} \mathrm{M}_{C}$ also forms water-mediated coordination to the nucleophile $\left(\mathrm{U}-1: \mathrm{O}^{2^{\prime}}\right)$ to be ready to act as the base catalyst during most of the simulation time (average distance $5.67 \AA$ ), although not as strongly as in the case of tWW_RT_C75 ${ }^{+} \mathrm{M}_{C}$. Note that in tWW_RT_C75 ${ }^{+} \mathrm{M}_{C}$, the tWW conformation is not stable and seems to move towards tWH/cWW conformations.

As graphically summarized in Figure 4, we conclude the following from the results in Table 2: after $\mathrm{C} 75$ is protonated, the interaction of the $\mathrm{B}$-site $\mathrm{Mg}^{2+}$ with $\mathrm{G} 25$ is weakened and may favor dissociation. Without the B-site $\mathrm{Mg}^{2+}$ it is unfavorable for the $\mathrm{G} 25: \mathrm{N}_{7}$ binding pocket to face the active site and G25:U20 prefers the tWH/cWW conformation. The resulting rearrangement of the active site creates a large space at the $\mathrm{C}$-site, resulting in recruitment of another $\mathrm{Mg}^{2+}$ into the $\mathrm{C}$-site. This new $\mathrm{Mg}^{2+}$ is in a position to serve as the base catalyst (Table 2 and III in Figure 4). This model is consistent with the third channel of $\mathrm{HDVr}$ reaction suggested by Nakano et al. ${ }^{90}$ and Cerrone-Szakal et al. ${ }^{36}$, in which involves both structural and catalytic $\mathrm{Mg}^{2+}$ ions.

\section{Deprotonation of $\mathrm{U}-1: \mathrm{O}^{2^{\prime}}$ causes rotation of $\mathrm{U}-1$, leading to an active, inline conformation}

After the nucleophile $\left(\mathrm{U}-1: \mathrm{O}^{2^{\prime}}\right)$ is deprotonated, a necessary condition for the reaction to proceed is the formation a conformation whereby the nucleophile is poised to make an inline attack to the scissile phosphate; e.g., the U-1: $\mathrm{O}^{2^{\prime}}-\mathrm{G} 1: \mathrm{P}-\mathrm{G} 1: \mathrm{O}^{5^{\prime}}$ angle of $\sim 160-180^{\circ}$. Such a conformation has not yet been directly observed from the electron density in any reported crystal structure of the HDVr, although a model structure was recently proposed based on the Hammerhead ribozyme active site structure. ${ }^{44}$ In all known structures in which U-1 is resolved (mainly $\mathrm{C} 75 \mathrm{U}$ mutants ${ }^{42}$ ) a large scale rotation of $\mathrm{U}-1$ would be needed to reach an inline conformation. In simulations departing from one such structure (activated by computational mutagenesis), we recently reported observation of spontaneous rotation of U-1 resulting in an inline conformation. ${ }^{59}$

Table 3 list the results of simulations with $\mathrm{U}-1: \mathrm{O}^{2^{\prime}}$ in a deprotonated state (denoted as $\mathrm{dRT}$ ) with different $\mathrm{G} 25: \mathrm{U} 20$ conformations and $\mathrm{Mg}^{2+}$ binding modes. In the tWW_dRT_C75 ${ }^{+} \mathrm{M}_{B}$ simulations, the $\mathrm{Mg}^{2+}$ remains bound and retains water mediated contacts with $\mathrm{G} 25: \mathrm{N}_{7}$ (average distance $4.72 \AA$ ) and G1: $\mathrm{O}_{2 P}$ (average distance $4.28 \AA$ ). However, the tWW conformation is weakened as indicated by the $\mathrm{G} 25: \mathrm{N}_{1} / \mathrm{U} 20: \mathrm{O}_{4}$ hydrogen bond percentage dropping to $33.2 \%$. The average inline angle was $95.7^{\circ}$ and the inline angle was never larger than $120^{\circ}$ during the 300 ns simulation time. 
In the tWW_dRT_C75 ${ }^{+} \mathrm{M}_{C}$ simulation, the $\mathrm{Mg}^{2+}$ again remained in its initial $\mathrm{C}$-site binding mode (average distance to $\mathrm{G} 1: \mathrm{N}_{7}$ is $2.19 \AA$ ), but with an average inline angle of $141.7^{\circ}$. In $96.0 \%$ of the time during simulation the inline angle was greater than $120^{\circ}$, while the tWW conformation was again significantly weakened. It is worth noting that, although the tWW conformation was weakened, the $\mathrm{U} 20: \mathrm{N}_{3} / \mathrm{G} 25: \mathrm{O}_{6}$ hydrogen bond is still strongly held $89.0 \%$ of the time. After closely examining the structures in the tWW_dRT_C75 ${ }^{+} \mathrm{M}_{C}$, although the inline angle is apparently sufficient for reaction to occur, we found that the U-1 rotation brings $\mathrm{U}-1: \mathrm{O}^{\mathrm{O} 2^{\prime}}$ closer to the phosphate group of $\mathrm{G} 2$ and in fact results in a conformation where $\mathrm{C} 75$ is far from ideal as a general acid, as the average distance between $\mathrm{C} 75: \mathrm{N}_{3}$ to $\mathrm{G} 1: \mathrm{O}_{1 P}(8.38 \AA), \mathrm{G} 1: \mathrm{O}_{2 P}(7.83 \AA)$, and $\mathrm{G} 1: \mathrm{O}^{5^{\prime}}(6.78 \AA)$ all increase significantly. Hence a tWW conformation with a $\mathrm{C}$-site bound $\mathrm{Mg}^{2+}$ is unlikely the most active conformation, even though a proper inline angle was obtained.

With G25:U20 initially in the tWH conformation (tWH_dRT_C75 ${ }^{+} \mathrm{M}_{B}$ ), the B-site $\mathrm{Mg}^{2+}$ appears to be less stable and the base pairing is disrupted. All key hydrogen bonds are broken and no inline conformations are observed. On the other hand, when the $\mathrm{Mg}^{2+}$ is initially placed at the C-site (tWH_dRT_C75 ${ }^{+} \mathrm{M}_{C}$ ), the $\mathrm{Mg}^{2+}$ remains bound during the simulation (average distance to $\mathrm{G} 1: \mathrm{N}_{7}$ is $2.21 \AA$ ) and the tWH conformation transitions to a strong $\mathrm{cWW}$ conformation, producing a significant population of inline conformations ( $78.3 \%$ of inline angle population $>120^{\circ}$ ). $\mathrm{C} 75: \mathrm{N}_{3}$ is also in a plausible position to act as the general acid. The simulation was repeated to further verify the observations (Table S3). Upon closer examination of the trajectory, two interactions (possibly water mediated) could be seen as the driving force for $\mathrm{U}-1$ rotation. Figure 7 shows the time series of the inline angle along with two distances between U-1 and G1/A77 (Figure 2). These distances are useful markers for interactions that are only present in active, inline conformations. The results are consistent with the detrimental effects of A77 mutants on HDV ribozyme function ${ }^{91}$ as well as observation of phosphorothioate interference at $\mathrm{G} 2: \mathrm{O}_{2 P},{ }^{76}$ for which, to our knowledge, no structural rationale has previously been suggested. Note that the present simulation work does not provide the insights of the timescale or the free energy barrier of U-1 rotation.

In summary, Table 3 suggests that a) the initial tWH conformation with $\mathrm{Mg}^{2+}$ placed at the $\mathrm{C}$-site is the most likely state from which $\mathrm{U}-1$ rotation will occur after the nucleophile is deprotonated (Figure 6); $b$ ) the resulting strong $\mathrm{cWW}$ conformation hydrogen bonding (84.1\% for $\mathrm{U} 20: \mathrm{N}_{3} / \mathrm{G} 25: \mathrm{O}_{6}$ and $72.9 \%$ for $\mathrm{U} 20: \mathrm{O}_{2} / \mathrm{G} 25: \mathrm{N}_{1}$, Figure 2), as well as two possible anchor points, $\mathrm{A} 77: \mathrm{N}_{6}$ and $\mathrm{G} 2: \mathrm{O}_{2 P}$, may be important for the $\mathrm{U}-1$ rotation; $c$ ) the $\mathrm{B}$-site $\mathrm{Mg}^{2+}$ may in fact inhibit such a rotation as there is no population of inline angle greater $120^{\circ}$ when $\mathrm{Mg}^{2+}$ is at the B-site, regardless of the initial G25:U20 conformation.

\section{As the reaction proceeds, the protonated $\mathrm{C}^{+} 5^{+}$moves to a position poised for general acid catalysis and ejects the $\mathrm{C}$-site $\mathbf{M g}^{2+}$}

Following (or concurrently with) phosphoryl transfer, the proton transfer must occur in order to stabilize the $\mathrm{G1}: \mathrm{O}^{5^{\prime}}$ oxide. A wealth of experimental evidence ${ }^{30,33,35,36}$ suggests that this proton originates from $\mathrm{C} 75$, acting as a general acid, though it has been suggested that $\mathrm{C} 75$ becomes positioned for this role only after the precursor state has been reached. ${ }^{39}$ Table 4 
lists results for simulations exploring various G25:U20 conformations and $\mathrm{Mg}^{2+}$ binding modes in transition state mimics. ${ }^{59}$

In the tWW_ETS_C75 ${ }^{+} \mathrm{M}_{B}$ simulation, where G25:U20 is in a tWW (reverse wobble) conformation and $\mathrm{Mg}^{2+}$ initially placed at the B-site (near $\mathrm{G}_{25}: \mathrm{N}_{7}$ ), the tWW conformation remains stable ( 70 to $80 \%$ of the time during the simulation the key hydrogen bonds are kept) and $\mathrm{Mg}^{2+}$ stays at the B-site. However the repulsive electrostatic interaction with the $\mathrm{B}$-site $\mathrm{Mg}^{2+}$ prevents $\mathrm{C}^{2} 5^{+}$from approaching $\mathrm{G1}: \mathrm{O}^{5^{\prime}}$ and hence would interfere with its role as general acid (average distance of $\mathrm{C} 75: \mathrm{N}_{3}$ to $\mathrm{G} 1: \mathrm{O}^{5^{\prime}}$ is $7.56 \AA$ ). Apparently, in this model the presence of $\mathrm{Mg}^{2+}$ at the $\mathrm{B}$-site prevents the reaction from proceeding by blocking the movement of $\mathrm{C} 75^{+}$.

In the tWW_ETS_C75 ${ }^{+} \mathrm{M}_{C}$ simulation, where G25:U20 is in a tWW conformation and $\mathrm{Mg}^{2+}$ is initially placed at the C-site, the tWW conformation is kept and $\mathrm{C} 75: \mathrm{N}_{3}$ is closer to $\mathrm{G} 1: \mathrm{O}^{5^{\prime}}$, but not yet in the position to act as a general acid (average distance $4.77 \AA$ ). This is possible due to the repulsive electrostatic interaction from sodium ions in the active site recruited by $\mathrm{G} 25: \mathrm{N}_{7}$. A similar situation is observed in the simulation without B-site or Csite $\mathrm{Mg}^{2+}\left(\mathrm{tWW}\right.$ _ETS_C75 ${ }^{+}$. In addition, the movement of $\mathrm{C} 75^{+}$to the reaction center causes loss of C-site bound $\mathrm{Mg}^{2+}$ (average distance to $\mathrm{G} 1: \mathrm{N}_{7}$ jumps to $6.69 \AA$ ).

When G25:U20 is initially in its tWH conformation (tWH_ETS_C75 ${ }^{+} \mathrm{M}_{C}$ ), G25:U20 forms a strong $\mathrm{cWW}$ pairing and $\mathrm{C}^{+} 5^{+}$moves close to $\mathrm{G} 1: \mathrm{O}^{5^{\prime}}$, ready to act as the general acid (average distance $3.01 \AA$ ) and, at the same time, push the $\mathrm{Mg}^{2+}$ out of the C-site (average distance to $\mathrm{G} 1: \mathrm{N}_{7}$ is $7.34 \AA$ ). Similar results are observed in the corresponding latetransition state mimic simulation (tWH_LTS_C $75^{+} \mathrm{M}_{C}$ ), except that the strong cWW pairing is much weaker.

Hence, the simulation results suggest that $\mathrm{Mg}^{2+}$ is no longer needed after the $\mathrm{S}_{N}$ 2-like reaction step. The B-site $\mathrm{Mg}^{2+}$, as well as sodium ions recruited by the tWW G25:U20 pair, will in fact prevent $\mathrm{C}^{+} 5^{+}$from reaching a position to be the general acid. Therefore, a B-site $\mathrm{Mg}^{2+}$ is inhibitory for this stage of the reaction. With the G25:U20 pair initially in a tWH conformation (later changing to $\mathrm{cWW}$ ), $\mathrm{C}^{+} 5^{+}$moves to the general acid position and pushes the $\mathrm{C}$-site $\mathrm{Mg}^{2+}$ away from the active site (Figure 8 ).

Simulation results for the product state with different G25:U20 conformations are also listed in Table 4. In both simulations, the key hydrogen bonds are kept, suggesting that they are stable (tWW and tWH but not cWW anymore). The $\mathrm{Mg}^{2+}$, initially placed at the C-site, quickly dissociates and enters the bulk solvent. Table 4 and " $\mathrm{V}$ " " in Figure 8 suggest that the G25:U20 base pairing is not critical after the reaction reaches its late-transition state and beyond. Both tWW and tWH seem stable, although weakened, in the product state. This is consistent with the fact that crystal structures of the product state do not have strong tWW G25:U20 base pairing (PDB: 1CX0 and 1DRZ) ${ }^{27}$ and that a product structure with a tWH form has also been reported (PDB: 1VC6). ${ }^{42}$ Lévesque et al. ${ }^{45}$ in fact also suggested that the tWW is formed after the cleavage. 


\section{A novel dynamic conformational model for HDVr catalysis}

There have been numerous attempts to rationalize and consolidate the various experimental evidence concerning the HDVr catalytic mechanism. Yet a consistent description has been dificult to reach. The key remaining issues are: 1.) the conformational impacts of C75 protonation states; 2.) the catalytic role(s) of $\mathrm{Mg}^{2+}$ and its binding modes; and 3.) the catalytically relevant conformations of the active site, especially the G25:U20 base pair.

Previously, we showed that a dynamic model involving distinct changes in conformation and metal binding is likely to be necessary to properly describe the Hammerhead ribozyme reaction. ${ }^{92-95}$ In subsequent work regarding the HDVr, we demonstrated that a dynamic model is able to consolidate the experimental evidence regarding the roles of $\mathrm{C} 75$ and the necessary conformational change of U-1. This model started with $\mathrm{C} 75$ in a position more consistent with activity as a general base and U-1 in an inactive, out-of-inline orientation, and ended with $\mathrm{C} 75$ in a position consistent with activity as a general acid and U-1 in an active, inline conformation. The latter change took place after a rotation of the U-1 backbone that was spontaneous after changes in the protonation states of $\mathrm{C} 75: \mathrm{N} 3$ and $\mathrm{U}-1: \mathrm{O}^{2}{ }^{\prime} .59$

Based on the simulation results, here we present an extended dynamic model of the HDVr reaction. The simulation results suggest that the HDVr reaction likely utilizes dynamical changes in the micro-environment of the active site to achieve its catalytic activity. In the Result section, we outlined the behaviors of various functional groups as the reaction proceeds. Here, we focus on the key unique findings from our simulations and the major differences compared to other models:

- Two different $\mathrm{Mg}^{2+}$ ions participate in the reaction, but at different stages, one playing a structural role and another one acting directly as the base catalyst;

- The conformation of the G25:U20 pair is flexible and highly coupled with the reaction coordinate;

- The position of C75 and its protonation state change at different stages of the reaction;

- $\quad$ The spontaneous rotation of U-1, resulting from the charge environment change after the base catalysis step, leads to an inline conformation poised for the subsequent steps.

Note that all of these findings were observed directly from molecular simulations and were not based on any a priori assumptions. As mentioned previously, the purpose of the present work is to identify plausible catalytically active states along the reaction coordinate that can serve as a departure point for further QM/MM investigation to characterize the free energy landscape for the chemical steps of the reaction in order to gain a complete picture of mechanism and estimate of reaction rates. Nonetheless, in order to place the current work into context, it is useful to discuss the general expected time scales involved. The wild-type HDVr has a reaction rate enhancement of nearly 3000 -fold, which is in the range of $\sim 1$ $\min ^{-1} .{ }^{96}$ The breaking of the G25:U20 pair should require free energy similar to base flipping in double-strand RNA, which could be spontaneous in the timescale of ns ${ }^{97}$ for 
certain sequences. Using high-level quantum calculations, the energy barrier of glycosidic bond rotation DNA bases has been estimated in the range of 3-8 kcal/mol, ${ }^{98,99}$ corresponding to half-life time of 20 ps to $80 \mathrm{~ns}$, indicating the proposed steps of G25 and U-1 rotations should fall into this range of time scale. Together, these proposed mechanic steps should be feasible in the HDVr chemical reaction.

\section{Two different $\mathrm{Mg}^{2+}$ ions participate the reaction, one playing a structural role and another acting as a base catalyst}

Although numerous works have suggested that two distinguishable $\mathrm{Mg}^{2+}$ ions and/or metal binding sites may be involved in the HDVr reaction, ${ }^{23,32,43,46,65,66,70,73}$ most recent mechanistic models have focused heavily on "the catalytically critical divalent metal ion".36,42,46,65,66,68-72 Less conventionally, our simulation results suggest two $\mathrm{Mg}^{2+}$ ions involved at different binding sites and at different points along the reaction path. The B-site $\mathrm{Mg}^{2+}$, seen in several crystal structures ${ }^{58}$ and inferred from mutational studies, ${ }^{45,46}$, is stable in our simulations when C75 is neutral, but is observed to dissociate when C75 is protonated. The most straight forward interpretation of these results is that the $\mathrm{B}$-site $\mathrm{Mg}^{2+}$ likely plays a structural role to promote an active site conformation that facilitates C75 protonation, but this protonation is correlated with release of $\mathrm{Mg}^{2+}$ from this site.

Subsequently, another $\mathrm{Mg}^{2+}$ ion enters the $\mathrm{C}$-site and, acting as a base catalyst, facilitates deprotonation of the U-1:O2' nucleophile. This ion also leaves the active site, but only after U-1 rotates to form an inline conformation and the reaction conditions are set. This picture is consistent with the experimental conclusion that there is at least one structural divalent metal ion that does not participate in catalysis and that $\mathrm{Mg}^{2+}$ speeds up the reaction $\sim 125$ folds through purely structural roles (the $\mathrm{B}$-site $\left.\mathrm{Mg}^{2+}\right)^{32}$ Consequently, our model predicts that weakened B-site binding will result in a decrease in enzyme activity, but will not alter the reaction $\mathrm{pH}$-profile if the conformational change to active state is not rate-limiting. However, absence of the $\mathrm{C}$-site metal ion, the proposed base catalyst, will alter the $\mathrm{pH}$-profile and decrease enzyme activity in a high-pH range but not at low-pH.

Thio substitution studies-Previous thio substitution studies showed little or no thio effects on the HDVr reaction, nor the rescue effect from $\mathrm{Mn}^{2+} \cdot{ }^{75,76}$ Nevertheless, more recent studies show thio substitution effect in the background of both mono and divalent ions and an "unconventional" rescue effect by $\mathrm{Cd}^{2+}$ involving suppression of the unmodiffed ribozyme rate constant. ${ }^{71,72}$

In our model, the pro-Rp oxygen is also important as it has a water-mediated contact with the $\mathrm{B}$-site $\mathrm{Mg}^{2+}$, consistent with experimental evidence. ${ }^{71,72,75,76}$ In this picture thio substitution of the pro-Rp oxygen will not change the reaction $\mathrm{pH}$-profile when $\mathrm{Mg}^{2+}$ is present, consistent with the reported experiments. ${ }^{71}$ This thio effect will be largely metal ion independent, since there is no direct binding of the pro-Rp oxygen to the metal ion. Hence whether $\mathrm{Cd}^{2+}$ is present or not, the reaction rate of the pro-Rp thio substitution will be similar. This will lead to the "unconventional rescue effect of $\mathrm{Cd}^{2+}$," mentioned by Thaplyal et al. ${ }^{71}$. 
G(1,2)-7DG mutants-Chen et al. ${ }^{65}$ have studied the effects of 7-deazaguanosine (7DG) substitution at the $\mathrm{G} 1$ and $\mathrm{G} 2$ positions. This corresponds to the $\mathrm{C}$-site, where our model suggests that a G1-7DG mutation will negatively impact $\mathrm{Mg}^{2+}$ binding. As above, disrupting the $\mathrm{C}$-site binding will alter the $\mathrm{pH}$-profile and decrease enzyme activity at high-pH range but not at the low-pH range. This was in fact observed at $\mathrm{pH} 5$ and $\mathrm{pH} 7 .^{65}$ The curve shapes of the reaction rate versus $\mathrm{Mg}^{2+}$ concentration are similar for all $\mathrm{G}(1,2)-7 \mathrm{DG}$ mutants at a given $\mathrm{pH}$, indicating that $\mathrm{B}$-site function is not affected. Interestingly, this explanation would require the prediction that contribution of $\mathrm{Mg}^{2+}$ to the chemical step at $\mathrm{pH} 7$ will be around 10 fold since at $\mathrm{pH} 7$ the rate decrease engendered by G1G2-7DG mutation $\left(k_{\max }=\right.$ $\left.0.62 \mathrm{~min}^{-1}\right)$ compared to the WT $\left(k_{\max }=7.0 \mathrm{~min}^{-1}\right)$ in also 10 -fold, and will be due to the loss of the C-site $\mathrm{Mg}^{2+}$ (the base catalyst) function. This is qualitatively consistent with the estimates from other studies. ${ }^{32,32}$

C75 $\Delta$ mutants are rescued by $\mathrm{NH}^{+}$- It has been shown that, in the absence of $\mathrm{Mg}^{2+}$, only ammonium ions, together with imidazole, rescue inactive $\mathrm{C} 75 \Delta$ variants. ${ }^{72}$ Based on our model, the B-site $\mathrm{Mg}^{2+}$ provides scaflolding to guide $\mathrm{C} 75$ towards the active site, where it subsequently becomes protonated. In a purely monovalent ionic environment, such a role will not be filled and the active site of C75 $\Delta$ may not possess enough space for imidazole to enter. However, the size of $\mathrm{NH}^{+}$is much larger than other monovalent ions and may be able to function similarly to a hydrated $\mathrm{Mg}^{2+}$ and hence create the necessary space for imidazole to enter. In such a scenario, the pH-profile will again be altered as the B-site function is partially restored but not $\mathrm{C}$-site function, consistent with the observed result. ${ }^{72}$

Anti-correlation between $\mathbf{C 7 5}$ and $\mathbf{M g}^{\mathbf{2}+}$ binding-Several studies have indicated that the shift in the apparent $\mathrm{p} K_{\mathrm{a}}$ of $\mathrm{C} 75$ is anti-correlated with increasing $\mathrm{Mg}^{2+}$

concentration. ${ }^{30,35,36,42,65,70}$ Here our simulations show that the B-site $\mathrm{Mg}^{2+}$ and protonated $\mathrm{C} 75$ repel each other. Increased concentration of $\mathrm{Mg}^{2+}$ will, in principle, increase occupation of all binding sites, but in this scenario anti-correlation with $\mathrm{C} 75$ only originates from the Bsite. In a study of G1/G2-7DG mutants by Chen et al. ${ }^{65}$, anti-correlation between C75 and $\mathrm{Mg}^{2+}$ was not reported. Nevertheless, based on our model, such anti-correlation should be observed for G1/G2-7DG mutants where only C-site binding will be impacted.

Further prediction-According to our model, the phosphoryl transfer and the general acid components of the reaction will be $\mathrm{Mg}^{2+}$-independent because both $\mathrm{B}$-site and $\mathrm{C}$-site ions already dissociated from the active site at this point. Recent QM/MM studies, ${ }^{69}$ however, have predicted the reaction to be highly $\mathrm{Mg}^{2+}$-dependent, i.e., the activation free energy differs by more than $8 \mathrm{kcal} / \mathrm{mol}$ when comparing the reaction in the presence and absence of $\mathrm{Mg}^{2+} \cdot{ }^{69,84}$ Further experimental evidence may be needed to distinguish them.

\section{The G25:U20 is flexible and its conformation is coupled with the reaction coordinate Formation of the G25:U20 reverse wobble via B-site $\mathbf{M g}^{\mathbf{2}+}$ binding-The tWW} (reverse wobble) form of G25:U20 has been observed in both a pre-cleavage crystal structure ${ }^{44}$ and during a recent re-fitting of a pre-cleavage $\mathrm{C} 75 \mathrm{U}$ and product structures. ${ }^{47}$ Several studies have suggested that $\mathrm{G} 25: \mathrm{N}_{7}$ creates a metal binding pocket in the active site, ${ }^{26,46,58,70,81}$ however, the tWW form of G25:U20 has never been directly observed along 
with U-1 in wild-type HDVr, and it is not clear whether G25:U20 is in its tWW form prior to the reaction.

Our simulation results suggest that the tWW form is likely the result of $\mathrm{Mg}^{2+}$ binding at Bsite and that the G25:U20 base pairing could become relatively weak (Table 1 and Figure 3) and therefore unstable in the absence of $\mathrm{Mg}^{2+}$ at the B-site. In fact, simulations without the $\mathrm{B}$-site $\mathrm{Mg}^{2+}$ present show the G25:U20 base pair spontaneously moving towards the tWH conformation (tWW_RT_C75 ${ }^{0}$ in Table 1). On the other hand, when this ion is present, G25:U20 prefers the tWW conformation due to water-mediated interactions between the ion and G25: $\mathrm{N}_{7}$. This observation is consistent with the proposals based on kinetic data of a metal ion-dependent conformational change near the cleavage site, ${ }^{50}$ the formation of P1.1 assisted by $\mathrm{Mg}^{2+}, 51$ as well as the fact that the conformation of $\mathrm{G} 25$ was not resolved when metal ions were removed in 1VC5.

\section{Conformational switching of the G25:U20 base-pair correlates with the protonation of $\mathrm{C} 75$ and the recruitment of $\mathrm{C}$-site $\mathbf{M g}^{2+}$ serving as the base} catalyst-After $\mathrm{C} 75$ is protonated, the $\mathrm{B}$-site $\mathrm{Mg}^{2+}$ will leave and the $\mathrm{G} 25: \mathrm{U} 20$ pair switch to $\mathrm{tWH} / \mathrm{cWW}$ conformation. The resulting rearrangement of the active site creates a large space at the $\mathrm{C}$-site and hence recruits another $\mathrm{Mg}^{2+}$ into the $\mathrm{C}$-site. This $\mathrm{Mg}^{2+}$ is at the proper position to serve as a base catalyst. In addition, when the G25:U20 pair is in the $\mathrm{tWH} / \mathrm{cWW}$ form, it will not provide metal binding ability at the B-site, which allows $\mathrm{C} 75^{+}$ to move towards the active site and act as the general acid. This picture is consistent with the work of Lévesque et al. ${ }^{45}$, which suggested that the tWH pairing of G25:U20 is formed before the cleavage and this tWH paring is catalytically important. Hence in our model, both the tWW and tWH conformations of G25:U20 are important: the tWW binds to B-site $\mathrm{Mg}^{2+}$ to create the active conformation of the reactant state; while the tWH maintains the active integrity so that the $\mathrm{C}$-site $\mathrm{Mg}^{2+}$ can be recruited after $\mathrm{C} 75$ is protonated and $\mathrm{B}$-site $\mathrm{Mg}^{2+}$ leaves.

It has been shown that, although the pair conformation may be flexible, both G25 and U20 are totally conserved across different species, implying they are critical for HDVr reaction. ${ }^{19}$ Our model demonstrates that both the tWW and tWH conformations are important but for different stages of the reaction, implying that the G25:U20 pair may in fact regulate the progress of the HDVr reaction through its conformation.

The A25:C20 double mutant-From our model, predictions and verification against experimental evidence can be made. Compared to the wild-type, the A25:C20 double mutant should have almost identical properties and active site micro-environment. A25: $\mathrm{N}_{7}$ is capable of providing a similar metal binding pocket for B-site binding. However, A25:C20 has a very different hydrogen bonding pattern in the tWH form and cannot form a stable cWW pairing ("III" in Figure 4) to maintain the active site integrity and to create the C-site to recruit another $\mathrm{Mg}^{2+}$ to serve as a base catalyst. Hence the A25:C20 double mutant should maintain B-site $\mathrm{Mg}^{2+}$ function but lose C-site function. As a result, the $\mathrm{Mg}^{2+}$ binding afinities for G25:U20 and A25:C20 ought to be similar but the A25:C20 pH profile will be altered. The activity of this mutant at high-pH range will be decreased but not at low-pH range. In other words, the $\mathrm{A} 25: \mathrm{C} 20$ reaction $\mathrm{pH}$ profile will be similar to the reaction 
without $\mathrm{Mg}^{2+}$, but only at low-pH. A25:C20 should be more active than the the reaction without $\mathrm{Mg}^{2+}$, as the $\mathrm{B}$-site $\mathrm{Mg}^{2+}$ function is still retained. All of these assertions are consistent with known experimental evidence. ${ }^{45,46}$

As for the $\mathrm{p} K_{\mathrm{a}}$ of $\mathrm{C} 75$, our model predicts that the anti-correlation relationship between $\mathrm{C} 75$ and $\mathrm{Mg}^{2+}$ will still be present in A25:C20 mutants, contrary to conclusions by Chen et al. ${ }^{46}$ and Thaplyal et al. ${ }^{72}$. Thaplyal et al. ${ }^{71}$ measured the reaction rate of a A25:C20 double mutant. With $10 \mathrm{mM} \mathrm{Mg}^{2+}$ the rate constant is only twice as high at $\mathrm{pH} 5.6$ than at $\mathrm{pH} 7$ ( $k_{\text {obs }}=0.06$ and $0.03 \mathrm{~min}^{-1}$, respectively) indicating that the $\mathrm{pH}$ profile plateaus in this range in the presence of $10 \mathrm{mM} \mathrm{Mg}^{2+}$. Hence the apparent $\mathrm{p} K_{\mathrm{a}}$ of $\mathrm{C} 75$ may be near or within this range. On the other hand, with $50 \mathrm{mM} \mathrm{Mg}^{2+}$ the rate constant is $\sim 28$ times higher at $\mathrm{pH} 5.6$ than at $\mathrm{pH} 7\left(k_{\text {obs }}=0.72\right.$ and $0.026 \mathrm{~min}^{-1}$, respectively $)$, indicating that the $\mathrm{pH}$ profile has a large negative slope at this range. Hence the apparent $\mathrm{p} K_{\mathrm{a}}$ of $\mathrm{C} 75$ may be shifted significantly downward. We interpret this data as evidence of the anti-correlation between $\mathrm{C} 75$ and $\mathrm{Mg}^{2+}$, implying the $\mathrm{B}$-site binding is retained in the $\mathrm{A} 25: \mathrm{C} 20$ double mutant.

Chemical modifications of G25:U20 which alter B-site binding, formation of the tWW or tWH conformations or the equilibrium between them (e.g., changing the G25 $\chi$ angle distribution ${ }^{100}$ ) should also affect the reaction rate and/or the rate $\mathrm{pH}$ profile.

\section{The position of $\mathrm{C} 75$ and its protonation state vary at different stages of the reaction}

Most simulations of the HDVr reported in the literature begin exclusively with C75 prepositioned in a geometry where it its ready to act as the general acid. $40,66,68,69,71,72,79-83$ By contrast, our previous simulations started with the $\mathrm{C} 75$ position taken from a $\mathrm{C} 75 \mathrm{U}$ mutant trapped in a pre-cleavage state. ${ }^{42,59}$ Nonetheless, that work demonstrated the movement of $\mathrm{C} 75$ towards the active site when it was protonated and O2' nucleophile O2' was deprotonated. Such trajectories eventually reached a geometry in which C75 was ready to act as the general acid in active sites that mimicked a transition state. The model presented here elaborates this picture further by suggesting that the position of $\mathrm{C} 75$ and its protonation state vary at different stages of the reaction. Our model is consistent with the NMR work by Lupták et al. ${ }^{37}: \mathrm{C} 75$ is presumed to be deprotonated in the reactant and product states and becomes positioned for reaction only along the trajectory from precursor to products. ${ }^{39}$

\section{The spontaneous rotation of $\mathrm{U}-1$, resulting from the change in electrostatic environment after the base catalysis step, leads to the inline conformation}

As mentioned earlier, the inline conformation necessary for the reaction has never been observed in any reported crystal structure to date. Although it has been suggested that there may be space for U-1 to undergo a rigid rotation to reach the necessary orientation, ${ }^{42}$ such a rotation has not yet been directly observed experimentally. ${ }^{24}$ Simulations to date have also not reported such a rotation, as they have instead assumed an inline U-1 starting conformation modeled from the HHR. ${ }^{44}$ We reported the U-1 rotation towards its inline conformation after the nucleophile $\mathrm{O} 2$ ' is deprotonated. ${ }^{59}$

Predictions-If the rotation of U-1 is a necessary step prior to the base catalysis, factors affecting the rotation will also affect the reaction rate. Such alterations might include 
changing the identity of the -1 position or the sequence and/or length of the upstream strand. Indeed these have been already observed experimentally but with different interpretations. ${ }^{101,102}$ Chemical modifications altering the rotation energy barrier may be used to test our proposed U-1 motion here. Furthermore, the proposed model predicts the base catalysis step and the phosphoryl transfer step will be well separated hence the base catalysis step should be specific base catalysis. An ${ }^{18} k_{\text {nuc }}$ experiment on the nucleophile O2' would characterize its protonation state along the reaction pathway and verify this prediction. ${ }^{103,104}$

\section{Comparison to other proposed models}

This proposed dynamic model differs significantly from other proposals. A recent model, here denoted as Model G (based on the original proponent, Golden ${ }^{58}$ ) (Tables 5 to 7), has been established based on a pre-cleavage structure with a modeled active site and molecular simulations. ${ }^{44,71,81}$ It provides very different views on the roles of both the B-site and the Csite $\mathrm{Mg}^{2+}$ ions, ${ }^{26,46,66,66}$ as well as the effect of an A25:C20 double mutant. ${ }^{46}$ Model G is more-or-less static as the active site arrangement is maintained from beginning of the base catalysis step to the very end of the general acid step. The inline conformation is enforced from the homologous model and U-1 conformation change (rotation) is not needed in this model.

Model $\mathrm{G}$ has been further extended with molecular dynamics simulations and has been suggested it may be a reactive intermediate trapped by low-pH. A set of scenarios of possible dynamical paths describing the interplay between the U-1 and G1 conformations, and the protonated $\mathrm{C} 75$, as well as the possible participation of the second $\mathrm{Mg}^{2+}$, were proposed and here are denoted as Model W (Tables 5 to 7). ${ }^{40}$

Conversely, our model, denoted as Model Y (Tables 5 to 7), begins with a crystal structure of the HDVr with U-1 completely resolved. Simulations were performed with different conditions (various G25: $\mathrm{U} 20$ conformations, $\mathrm{Mg}^{2+}$ binding modes, $\mathrm{C} 75$ protonation states, and different reaction stages) and a dynamic picture of the HDVr reaction is deduced from these simulations and experimental evidence. Hence this proposed dynamic model significantly differs from other proposed models and further experimental eflorts will be needed to distinguish all possible hypothesized models.

\section{Conclusion}

A set of long time molecular dynamics simulations of the HDVr at different stages along the reaction path have been performed. Simulation results predict a dynamic picture of the HDVr reaction mechanism whereby switching between three possible G25:U20 base pairing conformations play important roles in forming proper metal binding environments at different stages of the reaction. Two $\mathrm{Mg}^{2+}$ ions are coupled with this switching in a sequential fashion. The first ion plays a structural role by inducing a base pair flip necessary to obtain the catalytic fold in which C75 moves towards to the scissile phosphate in the active site. The second ion is poised to possibly play a chemical role by acting as a base catalyst through a bound water. Both ions are directly involved in the reaction but at different stages. This model offers an alternate mechanistic interpretation of a broad range of 
currently available experimental data. Several experimentally testable predictions are made that can be used to further lend credence to, or else refute the model. Spectroscopic signals such as NMR chemical shifts ${ }^{105}$ to monitor the syn/anti conformation of G25 or chemical modification of G25 that leads to altered syn/anti equlibrium will be particularly valuable.

\section{Supplementary Material}

Refer to Web version on PubMed Central for supplementary material.

\section{Acknowledgments}

The authors are grateful for financial support provided by the National Institutes of Health (GM62248 to DY and GM096000 to MEH). This work used the Extreme Science and Engineering Discovery Environment (XSEDE), which is supported by National Science Foundation grant number OCI-1053575, with project number TGMCB110101 (D.Y.).

\section{References}

(1). Quin MB, Schmidt-Dannert C. ACS Catal. 2011; 1:1017-1021. [PubMed: 22125758]

(2). Choi J-M, Han S-S, Kim H-S. Biotechnol Adv. 2015 0, 0.

(3). Garcia-Viloca M, Gao J, Karplus M, Truhlar DG. Science. 2004; 303:186-195. [PubMed: 14716003]

(4). Kruger K, Grabowsky P, Zaug A, Sands J, Gottschling D, Cech T. Cell. 1982; 31:147-157. [PubMed: 6297745]

(5). Latham JA, Cech TR. Science. 1989; 245:276-282. [PubMed: 2501870]

(6). Zaug AJ, Cech TR. Science. 1986; 231:470-475. [PubMed: 3941911]

(7). Guerrier-Takada C, Haydock K, Allen L, Altman S. Biochemistry. 1986; 25:1509-1515. [PubMed: 2423112]

(8). Haseloff J, Gerlach WL. Nature. 1988; 334:585-591. [PubMed: 2457170]

(9). Penchovsky R. BiotechAdv. 2014; 32:1015-1027.

(10). Narlikar GJ, Herschlag D. Annu. Rev. Biochem. 1997; 66:19-59. [PubMed: 9242901]

(11). Doudna JA, Lorsch JR. Nat. Struct. Mol. Biol. 2005; 12:395-402. [PubMed: 15870731]

(12). Lilley DM. J. Phil. Trans. R. Soc. B. 2011; 366:2910-2917. [PubMed: 21930582]

(13). Ward WL, Plakos K, DeRose VJ. Chem. Rev. 2014; 114:4318-4342. [PubMed: 24730975]

(14). Kuo MY, Sharmeen L, Dinter-Gottlieb G, Taylor J. J. Virol. 1988; 62:4439-4444. [PubMed: 3184270]

(15). Sharmeen L, Kuo MY, Dinter-Gottlieb G, Taylor J. J. Virol. 1988; 62:2674-2679. [PubMed: 2455816]

(16). Wu H-N, Lin Y-J, Lin F-P, Makino S, Chang M-F. Proc. Natl. Acad. Sci. USA. 1989; 86:18311835. [PubMed: 2648383]

(17). Lai MMC. Annu. Rev. Biochem. 1995; 64:259-286. [PubMed: 7574482]

(18). Salehi-Ashtiani K, Lupták A, Litovchick A, Szostak JW. Science. 2006; 313:1788-1792. [PubMed: 16990549]

(19). Webb C-HT, Riccitelli NJ, Ruminski DJ, Lupták A. Science. 2009; 326:953. [PubMed: 19965505]

(20). Webb C-HT, Lupták A. RNA Biol. 2011; 8:719-727. [PubMed: 21734469]

(21). Sánchez-Luque FJ, López MC, Carreira PE, Alonso C, Thomas MC. BMC Genomics. 2014; 15:340. [PubMed: 24884364]

(22). Zhu JYA, Meyer IM. RNA Biol. 2015; 12:5-20. [PubMed: 25751035]

(23). Riccitelli NJ, Delwart E, Lupták A. Biochemistry. 2014; 53:1616-1626. [PubMed: 24555915]

(24). Been MD. Curr. Top. Micro. Biol. Immunol. 2006; 307:47-65. 
(25). Fedor M. J. Annu. Rev. Biophys. 2009; 38:271-299.

(26). Golden, BL.; Hammes-Schiffer, S.; Carey, PR.; Bevilacqua, PC. In Biophysics of RNA Folding. In: Russell, R., editor. Biophysics for the Life Sciences. Vol. 3. Springer; New York: 2013. p. 135-167. Chapter 8

(27). Ferré-D’Amaré AR, Zhou K, Doudna JA. Nature. 1998; 395:567-574. [PubMed: 9783582]

(28). Perrotta AT, Been MD. Nucleic Acids Res. 1990; 18:6821-6827. [PubMed: 2263447]

(29). Wadkins TS, Perrotta AT, Ferré-D’Amaré AR, Doudna JA, Been MD. RNA. 1999; 5:720-727. [PubMed: 10376872]

(30). Nakano S, Chadalavada DM, Bevilacqua PC. Science. 2000; 287:1493-1497. [PubMed: 10688799]

(31). Das S, Piccirilli J. Nat. Chem. Biol. 2005; 1:45-52. [PubMed: 16407993]

(32). Nakano S, Proctor DJ, Bevilacqua PC. Biochemistry. 2001; 40:12022-12038. [PubMed: 11580278]

(33). Oyelere AK, Kardon JR, Strobel SA. Biochemistry. 2002; 41:3667-3675. [PubMed: 11888283]

(34). Das S, Piccirilli J. Nature Chem. Biol. 2005; 1:45-52. [PubMed: 16407993]

(35). Gong B, Chen J-H, Chase E, Chadalavada DM, Yajima R, Golden BL, Bevilacqua PC, Carey PR. J. Am. Chem. Soc. 2007; 129:13335-13342. [PubMed: 17924627]

(36). Cerrone-Szakal AL, Siegfried NA, Bevilacqua PC. J. Am. Chem. Soc. 2008; 130:14504-14520. [PubMed: 18842044]

(37). Lupták A, Ferré-D’Amaré AR, Zhou K, Zilm KW, Doudna JA. J. Am. Chem. Soc. 2001; 123:8447-8452. [PubMed: 11525650]

(38). Shih I, Been MD. Proc. Natl. Acad. Sci. USA. 2001; 98:1489-1494. [PubMed: 11171978]

(39). Harris DA, Rueda D, Walter NG. Biochemistry. 2002; 41:12051-12061. [PubMed: 12356305]

(40). Sripathi KN, Tay WW, Banás P, Otyepka M, Šponer J, Walter NG. RNA. 2014; 20:1112-1128. [PubMed: 24854621]

(41). Leontis NB, Westhof E. RNA. 2001; 7:499-512. [PubMed: 11345429]

(42). Ke A, Zhou K, Ding F, Cate JHD, Doudna JA. Nature. 2004; 429:201-205. [PubMed: 15141216]

(43). Ke A, Ding F, Batchelor JD, Doudna JA. Structure. 2007; 15:281-287. [PubMed: 17355864]

(44). Chen J-H, Yajima R, Chadalavada DM, Chase E, Bevilacqua PC, Golden BL. Biochemistry. 2010; 49:6508-6518. [PubMed: 20677830]

(45). Lévesque D, Reymond C, Perreault J-P. PLoS ONE. 2012; 7:40309.

(46). Chen J, Ganguly A, Miswan Z, Hammes-Schiffer S, Bevilacqua PC, Golden BL. Biochemistry. 2013; 52:557-567. [PubMed: 23311293]

(47). Kapral GJ, Jain S, Noeske J, Doudna JA, Richardson DC, Richardson JS. Nucleic Acids Res. 2014; 42:12833-12846. [PubMed: 25326328]

(48). Lynch SR, Tinoco I Jr. Nucleic Acids Res. 1998; 26:980-987. [PubMed: 9461457]

(49). Brown TS, Chadalavada DM, Bevilacqua PC. J. Mol. Biol. 2004; 341:695-712. [PubMed: 15288780]

(50). Rosenstein SP, Been MD. Biochemistry. 1990; 29:8011-8016. [PubMed: 2261458]

(51). Lévesque D, Choufani S, Perreault J-P. RNA. 2002; 8:464-477. [PubMed: 11991641]

(52). Kumar PK, Taira K, Nishikawa S. Biochemistry. 1994; 33:583-592. [PubMed: 8286389]

(53). van Tol H, Buzatan JM, Feldstein PA, Eckstein F, Bruening G. Nucleic Acids Res. 1990; 18:1971-1975. [PubMed: 1692411]

(54). Slim G, Gait MJ. Nucleic Acids Res. 1991; 19:1183-1188. [PubMed: 1709484]

(55). Takagi Y, Warashina M, Stec WJ, Yoshinari K, Taira K. Nucleic Acids Res. 2001; 29:1815-1834. [PubMed: 11328865]

(56). Yoshinari K, Taira K. Nucleic Acids Res. 2000; 28:1730-1742. [PubMed: 10734192]

(57). Stowasser R, Usher DA. Bioorg. Chem. 2002; 30:420-430. [PubMed: 12642126]

(58). Golden BL. Biochemistry. 2011; 50:9424-9433. [PubMed: 22003985]

(59). Lee T-S, Giambaşu GM, Harris ME, York DM. J. Phys. Chem. Lett. 2011; 2:2538-2543. [PubMed: 22200005] 
(60). Pereira MJB, Harris DA, Rueda D, Walter NG. Biochemistry. 2002; 41:730-740. [PubMed: 11790094]

(61). Suh YA, Kumar PK, Taira K, Nishikawa S. Nucleic Acids Res. 1993; 21:3277-3280. [PubMed: 8341602]

(62). Shih I, Been MD. RNA. 1999; 5:1140-1148. [PubMed: 10496215]

(63). Shih I, Been MD. Annu. Rev. Biochem. 2002; 71:887-917. [PubMed: 12045114]

(64). Nakano S, Bevilacqua PC. Biochemistry. 2007; 46:3001-3012. [PubMed: 17315949]

(65). Chen J-H, Gong B, Bevilacqua PC, Carey PR, Golden BL. Biochemistry. 2009; 48:1498-1507. [PubMed: 19178151]

(66). Veeraraghavan N, Ganguly A, Golden BL, Bevilacqua PC, Hammes-Schiffer SJ. Phys. Chem. B. 2011; 115:8346-8357.

(67). Sigel RKO, Pyle AM. Chem. Rev. 2007; 2007:97-113.

(68). Mlýnský V, Walter NG, Šponer J, Otyepka M, Banáš P. Phys. Chem. Chem. Phys. 2015; 17:670679. [PubMed: 25412464]

(69). Ganguly A, Thaplyal P, Rosta E, Bevilacqua PC, Hammes-Schiffer SJ. Am. Chem. Soc. 2014; 136:1483-1496.

(70). Gong B, Chen J-H, Bevilacqua PC, Golden BL, Carey PR. Biochemistry. 2009; 48:11961-11970. [PubMed: 19888753]

(71). Thaplyal P, Ganguly A, Golden BL, Hammes-Schiffer S, Bevilacqua PC. Biochemistry. 2013; 52:6499-6514. [PubMed: 24001219]

(72). Thaplyal P, Ganguly A, Hammes-Schiffer S, Bevilacqua PC. Biochemistry. 2015; 54:2160-2175. [PubMed: 25799319]

(73). Gong B, Chen Y, Christian EL, Chen J-H, Chase E, Chadalavada DM, Yajima R, Golden BL, Bevilacqua PC, Carey PR. J. Am. Chem. Soc. 2008; 130:9670-9672. [PubMed: 18593125]

(74). Shih I, Been M. Biochemistry. 2000; 39:9055-9066. [PubMed: 10924098]

(75). Fauzi H, Kawakami J, Nishikawa F, Nishikawa S. Nucleic Acids Res. 1997; 25:3124-3130. [PubMed: 9224614]

(76). Jeoung YH, Kumar PK, Suh YA, Taira K, Nishikawa S. Nucleic Acids Res. 1994; 22:3722-3727. [PubMed: 7937083]

(77). Perrotta AT, Been MD. Biochemistry. 2006; 45:11357-11365. [PubMed: 16981696]

(78). Nakano S, Bevilacqua PC. J. Am. Chem. Soc. 2001; 123:11333-11334. [PubMed: 11697993]

(79). Sripathi KN, Banáš P, Réblová K, Šponer J, Otyepka M, Walter NG. Phys. Chem. Chem. Phys. 2015; 17:5887-5900. [PubMed: 25631765]

(80). Veeraraghavan N, Bevilacqua PC, Hammes-Schiffer S. J. Mol. Biol. 2010; 402:278-291. [PubMed: 20643139]

(81). Veeraraghavan N, Ganguly A, Chen J-H, Bevilacqua PC, Hammes-Schiffer S, Golden BL. Biochemistry. 2011; 50:2672-2682. [PubMed: 21348498]

(82). Banáš P, Jurečka P, Walter NG, Šponer J, Otyepka M. Methods. 2009; 49:202-216. [PubMed: 19398008]

(83). Banáš P, Rulíšek L, Hánošová V, Svozil D, Walter NG, Šponer J, Otyepka M. J. Phys. Chem. B. 2008; 112:11177-11187. [PubMed: 18686993]

(84). Radak BK, Lee T-S, Harris ME, York DM. RNA. 2015; 21:1566-1577. [PubMed: 26170378]

(85). Case, DA., et al. AMBER 7. University of California San Francisco; San Francisco: 2002.

(86). Pearlman DA, Case DA, Caldwell JW, Ross WR, Cheatham T III, DeBolt S, Ferguson D, Seibel G, Kollman P. Comput. Phys. Commun. 1995; 91:1-41.

(87). Pérez A, Marchán I, Svozil D, Sponer J, Cheatham TE III, Laughton CA, Orozco M. Biophys. J. 2007; 92:3817-3829. [PubMed: 17351000]

(88). Mayaan E, Moser A, MacKerell AD Jr. York DM. J. Comput. Chem. 2007; 28:495-507. [PubMed: 17186477]

(89). Cerrone-Szakal AL, Chadalavada DM, Golden BL, Bevilacqua PC. RNA. 2008; 14:1746-1760. [PubMed: 18658121] 
(90). Nakano S, Cerrone AL, Bevilacqua PC. Biochemistry. 2003; 42:2982-2994. [PubMed: 12627964]

(91). Nishikawa F, Shirai M, Nishikawa S. Eur. J. Biochem. 2002; 269:5792-5803. [PubMed: 12444967]

(92). Lee T-S, Silva-Lopez C, Martick M, Scott WG, York DM. J. Chem. Theory Comput. 2007; 3:325-327. [PubMed: 19079784]

(93). Lee T-S, Silva Lopez C, Giambaşu GM, Martick M, Scott WG, York DM. J. Am. Chem. Soc. 2008; 130:3053-3064. [PubMed: 18271579]

(94). Lee T-S, Giambaşu GM, Sosa CP, Martick M, Scott WG, York DM. J. Mol. Biol. 2009; 388:195206. [PubMed: 19265710]

(95). Wong K-Y, Lee T-S, York DM. J. Chem. Theory Comput. 2011; 7:1-3. [PubMed: 21379373]

(96). Chadalavada DM, Cerrone-Szakal AL, Bevilacqua PC. RNA. 2007; 13:2189-2201. [PubMed: 17956974]

(97). Pan Y, MacKerell AD Jr. Nucleic Acids Res. 2003; 31:7131-7140. [PubMed: 14654688]

(98). Foloppe N, Hartmann B, Nilsson L, MacKerell AD Jr. Biophys. J. 2002; 82:1554-1569. [PubMed: 11867468]

(99). Foloppe N, Nilsson L. J. Phys. Chem. B. 2005; 109:9119-9131. [PubMed: 16852085]

(100). Sokoloski JE, Godfrey SA, Dombrowski SE, Bevilacqua PC. RNA. 2011; 17:1775-1787. [PubMed: 21873463]

(101). Chadalavada, Durga M.; Knudsen, Scott M.; Nakano, Shu-ichi; Bevilacqua, Philip C. J. Mol. Biol. 2000; 301:349-367. [PubMed: 10926514]

(102). Perrotta AT, Been MD. Biochemistry. 2007; 46:5124-5130. [PubMed: 17417876]

(103). Humphry T, Iyer S, Iranzo O, Morrow JR, Richard JP, Paneth P, Hengge AC. J. Am. Chem. Soc. 2008; 130:17858-17866. [PubMed: 19053445]

(104). Harris ME, Dai Q, Gu H, Kellerman DL, Piccirilli JA, Anderson VE. J. Am. Chem. Soc. 2010; 132:11613-11621. [PubMed: 20669950]

(105). Wijmenga SS, van Buuren BN. Prog. Nucl. Magn. Reson. Spectrosc. 1998; 32:287-387. 


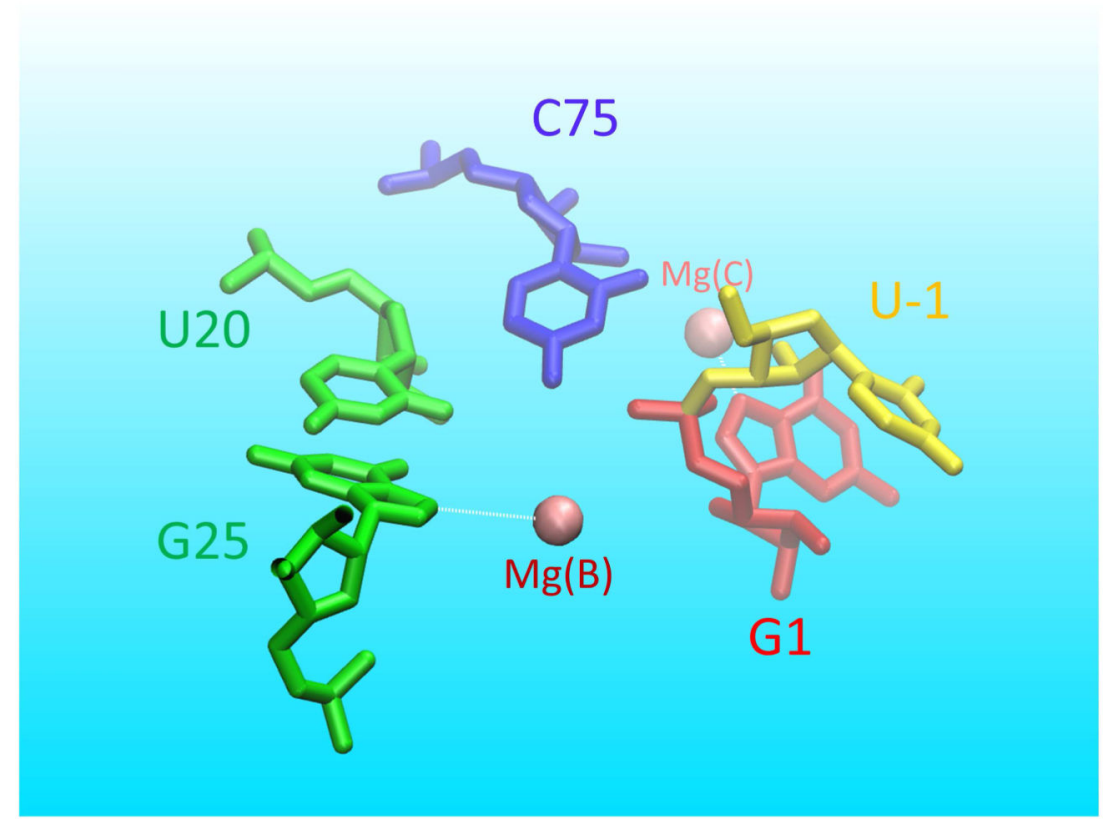

Figure 1.

The active site of HDVr with two potential $\mathrm{Mg}^{2+}$ binding sites. 


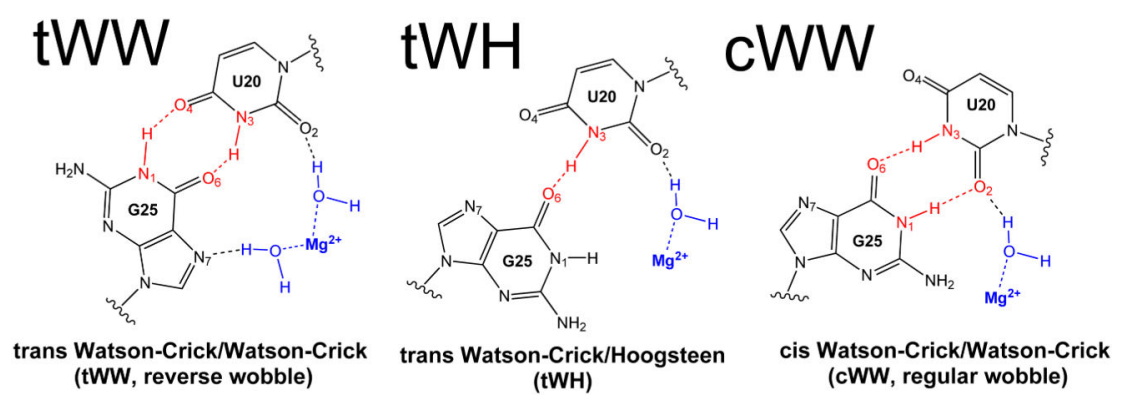

Figure 2.

Three conformations of the G25:U20 pair in the HDVr reaction. Key hydrogen bonds distinguishing the three conformations are colored red: 1 . tWW: G25: $\mathrm{N}_{1} / \mathrm{U} 20: \mathrm{O}_{4}$ and $\mathrm{U} 20: \mathrm{N}_{3} / \mathrm{G} 25: \mathrm{O}_{6} ; 2$. tWH U20: $\mathrm{N}_{3} / \mathrm{G} 25: \mathrm{O}_{6}$ only; 3 . cWW: $\mathrm{U} 20: \mathrm{N}_{3} / \mathrm{G} 25: \mathrm{O}_{6}$ and $\mathrm{U} 20: \mathrm{O}_{2} /$ G25: $\mathrm{N}_{1}$. Possible $\mathrm{Mg}^{2+}$ binding modes near G25:U20 are also shown in blue. 

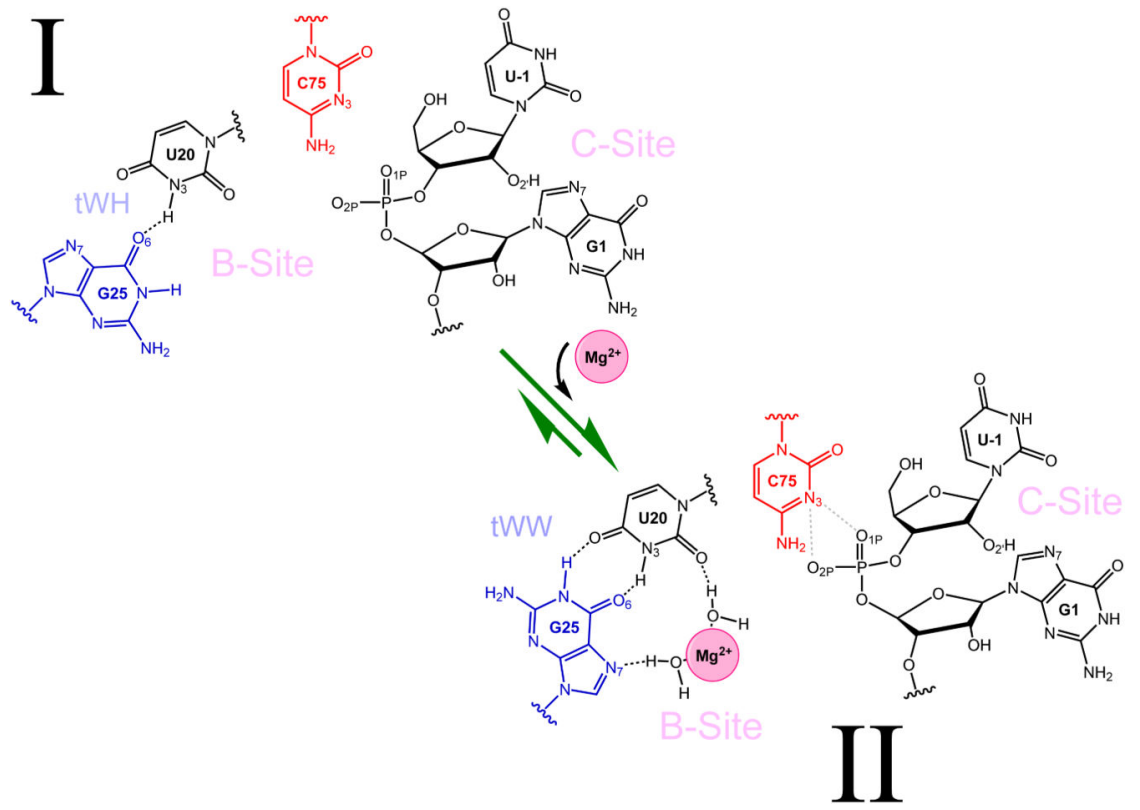

Figure 3.

The proposed dynamic model in the reactant state. The $\mathrm{B}$-site $\mathrm{Mg}^{2+}$ binding leads to the induced fit of the tWW conformation of G25:U20. 

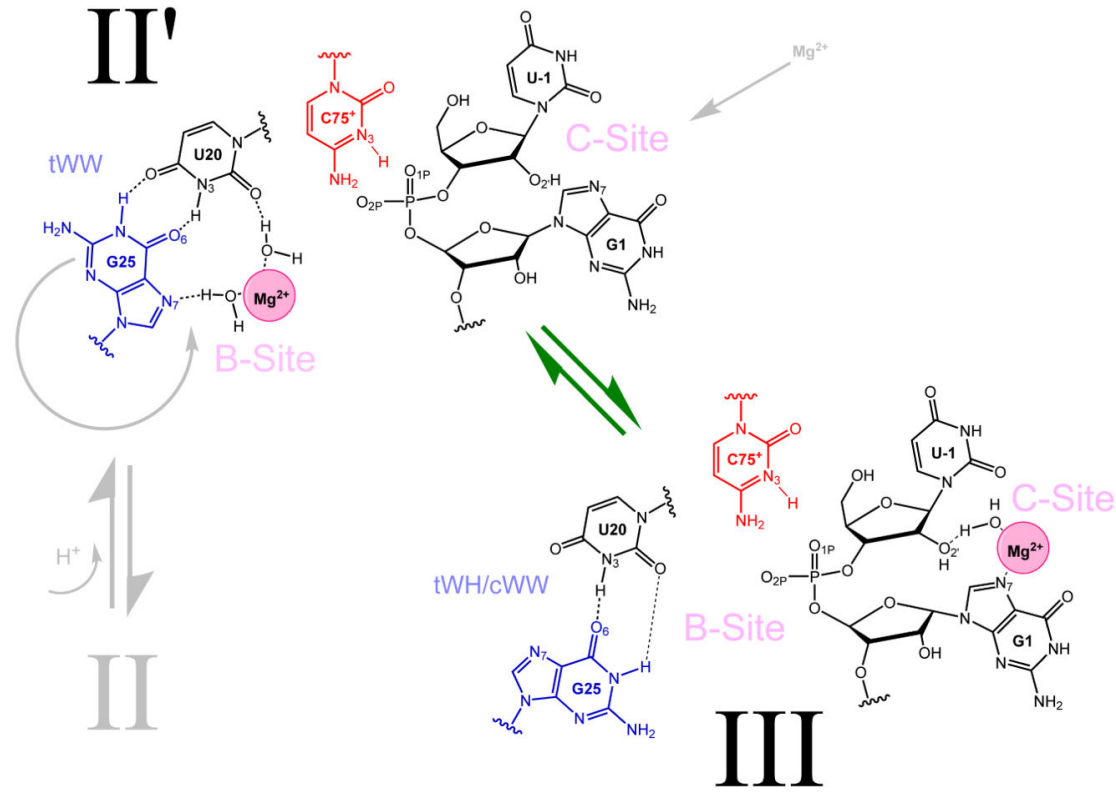

Figure 4.

The proposed dynamic model with protonated $\mathrm{C}^{2} 5^{+}$(II') and the resulting conformation after the B-site $\mathrm{Mg}^{2+}$ leaves, the G25:U20 switches from tWW to tWH/cWW, and another $\mathrm{Mg}^{2+}$ enters the C-site (III). 


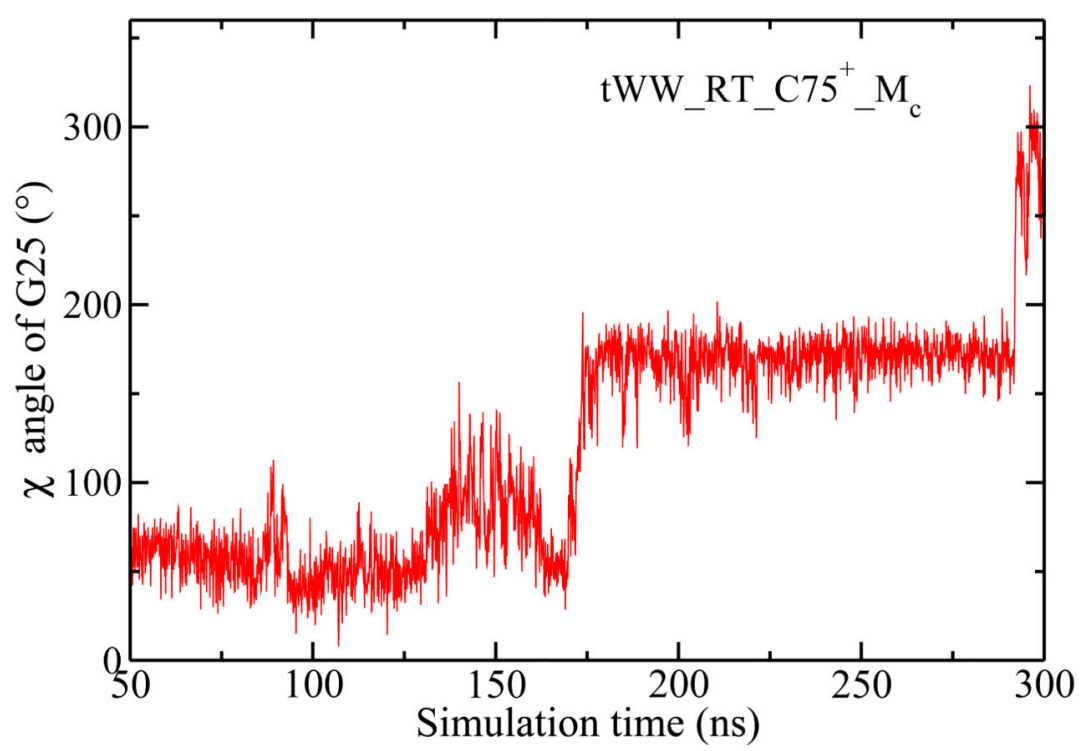

Figure 5.

The time series of the glycosidic bond torsion (the $\chi$ angle, defined as the torsion between $\left.\mathrm{O}^{4^{\prime}}-\mathrm{C}^{1^{\prime}}-\mathrm{N}_{9}-\mathrm{C}_{4}\right)$ of G25 for the tWW_RT_C75 ${ }^{+} \mathrm{M}_{C}$ simulation. The G25: $\chi$ angle changes from $\sim 50^{\circ}$ (a syn conformation), to $\sim 180^{\circ}$ after $175 \mathrm{~ns}$, and then to over $250^{\circ}$ (a clear anticonformation). In order to demonstrate the continues changes, the $\chi$ angle shown here are in the range between $0^{\circ}$ and $360^{\circ}$, while the range of $\left(-180^{\circ}, 180^{\circ}\right)$ is used in other places. 

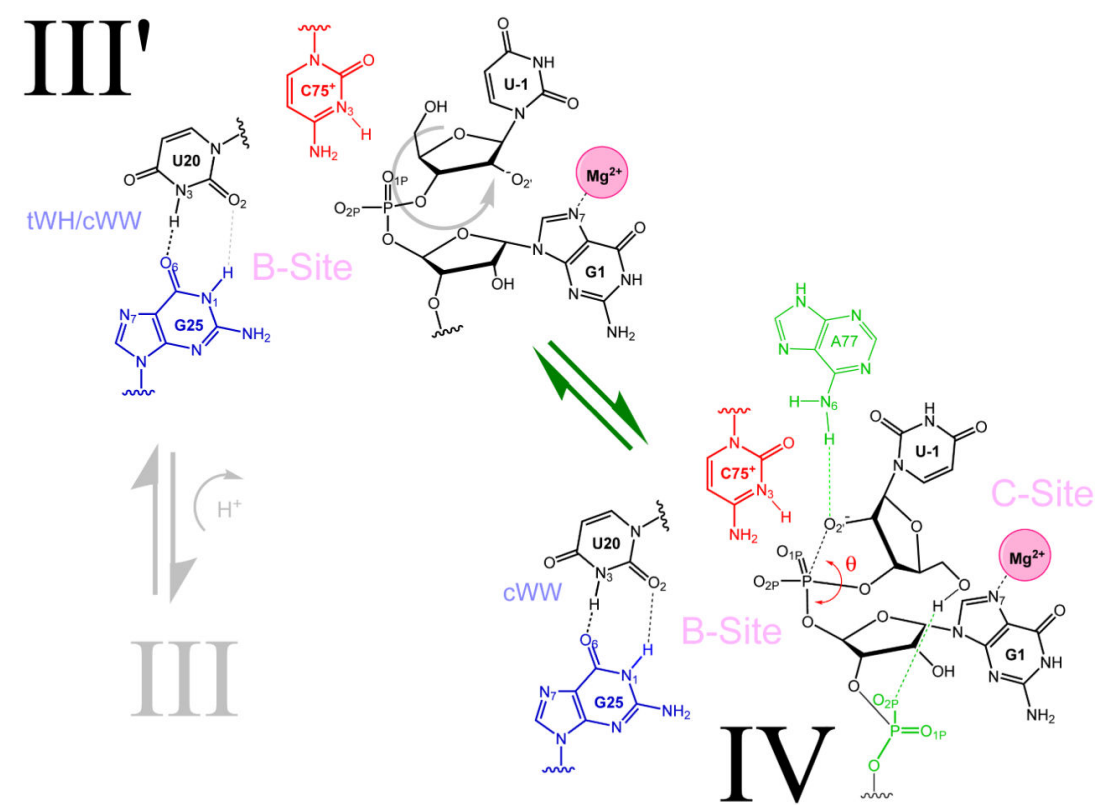

Figure 6.

The proposed dynamic model of the activated precursor state, where the nucleophile, $\mathrm{U}-1: \mathrm{O}^{2^{\prime}}$ is deprotonated (III') and the resulting conformation after $\mathrm{U}-1$ rotates to reach an inline conformation ready for the next step of the reaction, the nucleophilic $\left(\mathrm{S}_{N} 2\right.$-like $)$ reaction (IV). The G25:U20 now forms a stronger $\mathrm{cWW}$ pairing. 


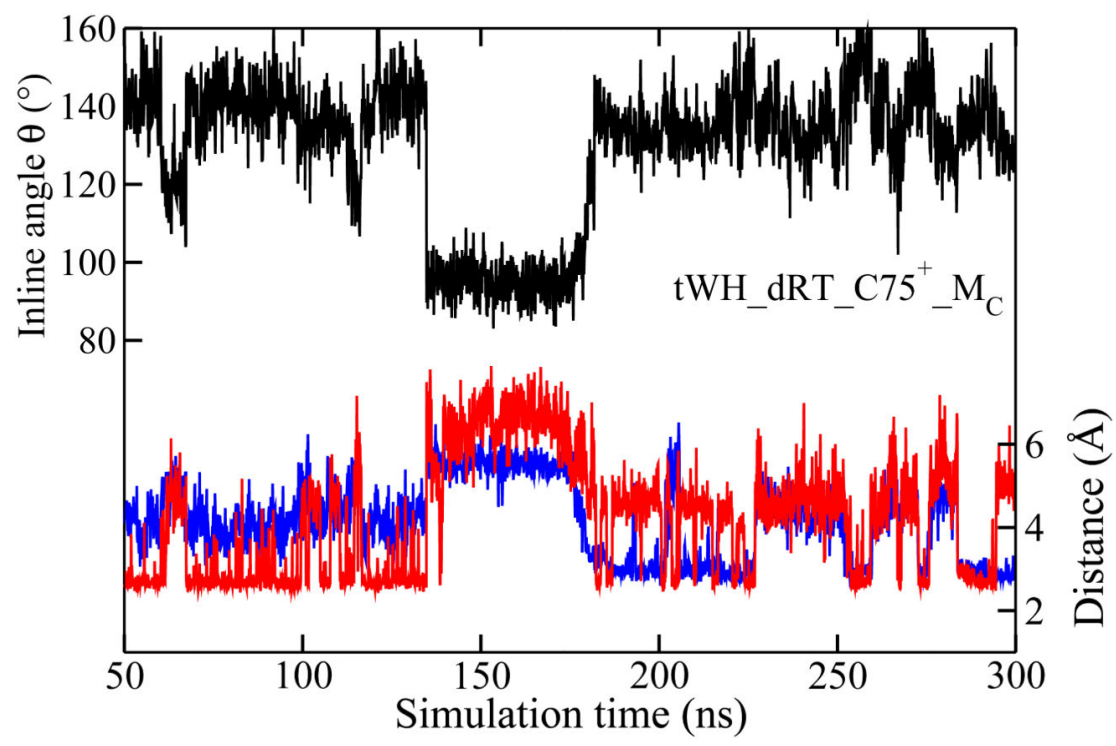

Figure 7.

The time series of the inline attacking angle $\left(\theta\left(\mathrm{U}-1: \mathrm{O}^{2^{\prime}}{ }_{-} \mathrm{G} 1: \mathrm{P}-\mathrm{G} 1: \mathrm{O}^{5^{\prime}}\right)\right.$, in black $)$ and two possible hydrogen bond pairs holding the inline conformation, $\mathrm{U}-1: \mathrm{O}^{2^{\prime}} / \mathrm{A} 77: \mathrm{N}_{6}$ (blue) and $\mathrm{G} 1: \mathrm{O}_{2 P} / \mathrm{U}-1: \mathrm{O}^{5^{\prime}}$ (red), in the simulation tWH_dRT_C75 ${ }^{+} \mathrm{M}_{C}$, where a simultaneous rotation of $\mathrm{U}-1$ resulting in the inline conformation is observed. 


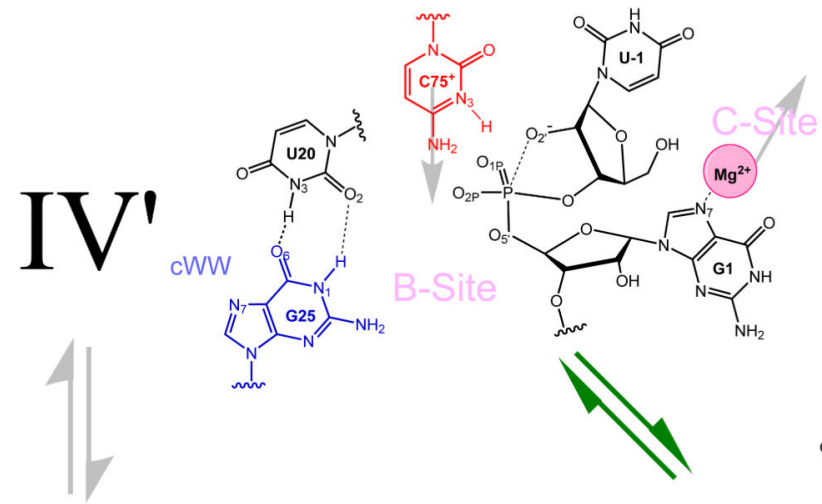

\section{Product}
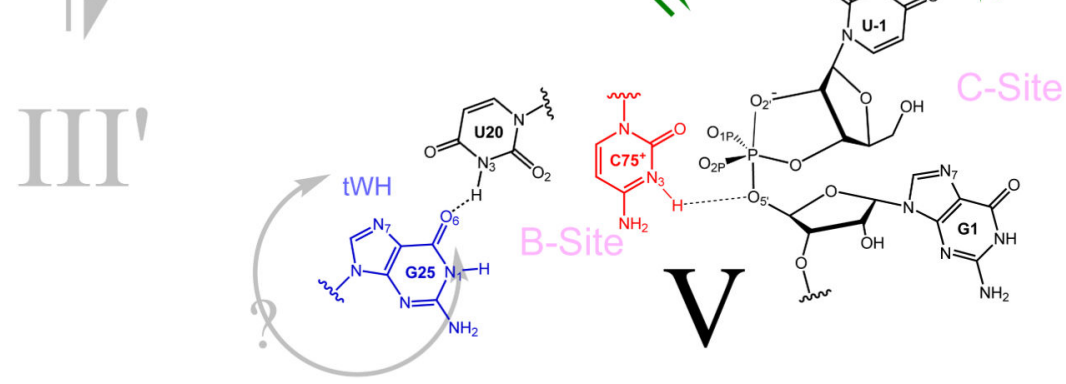

Figure 8.

The proposed dynamic model of the transition states. As the nucleophilic $\left(\mathrm{S}_{N}\right.$ 2-like $)$ reaction begins (IV'), $\mathrm{C}^{\circ} 5^{+}: \mathrm{N}_{3}$ moves towards the leaving group, $\mathrm{G1}: \mathrm{O}^{5^{\prime}}$ and at the same time pushes the C-site $\mathrm{Mg}^{2+}$ out of the active site (V). The G25:U20 may stay in a weak tWH or change to tWW conformation after the reaction completes. 


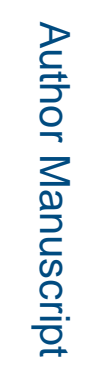

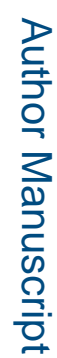

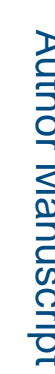

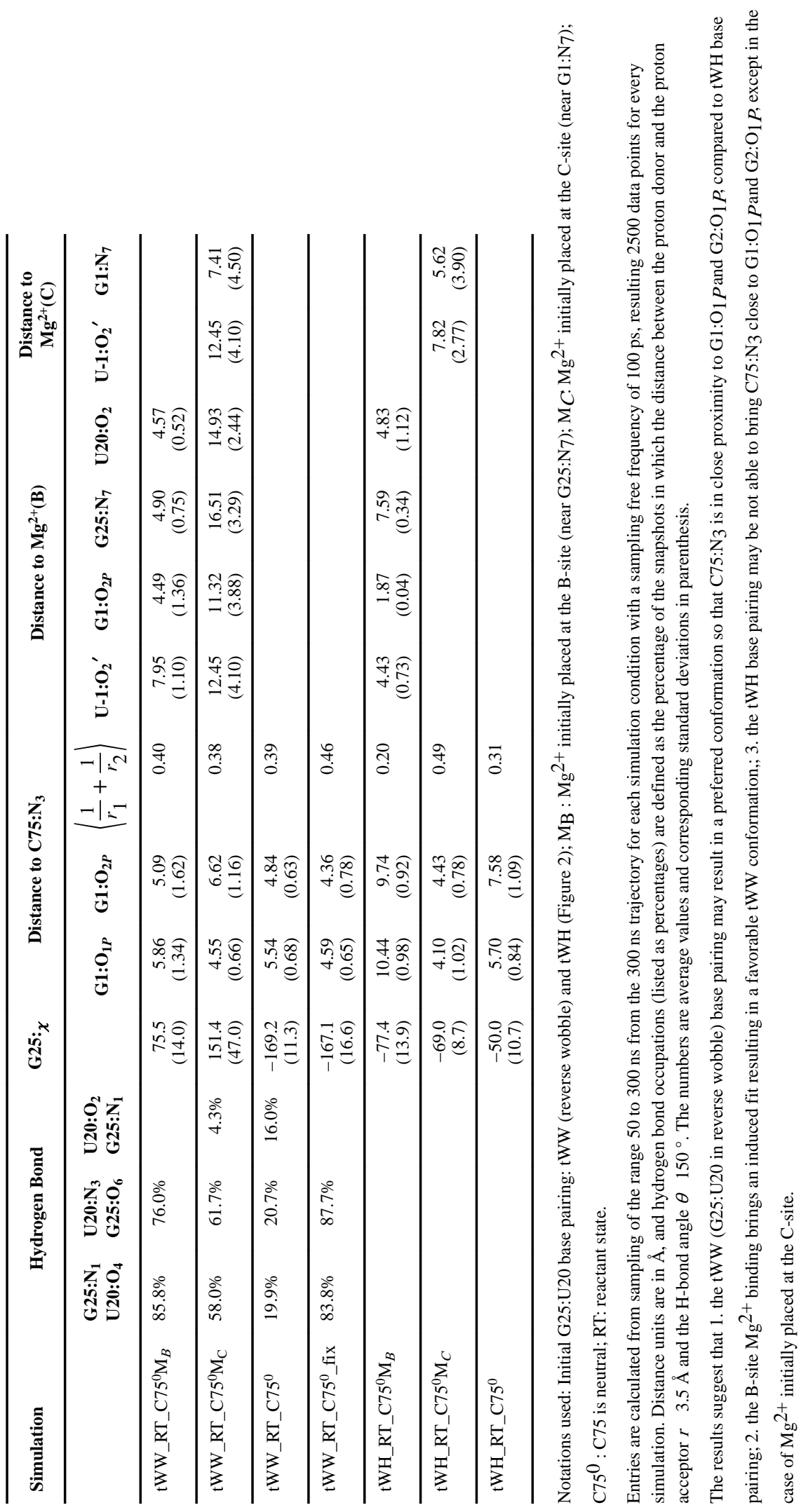

ACS Catal. Author manuscript; available in PMC 2016 October 20 


\section{롤 \\ 章}

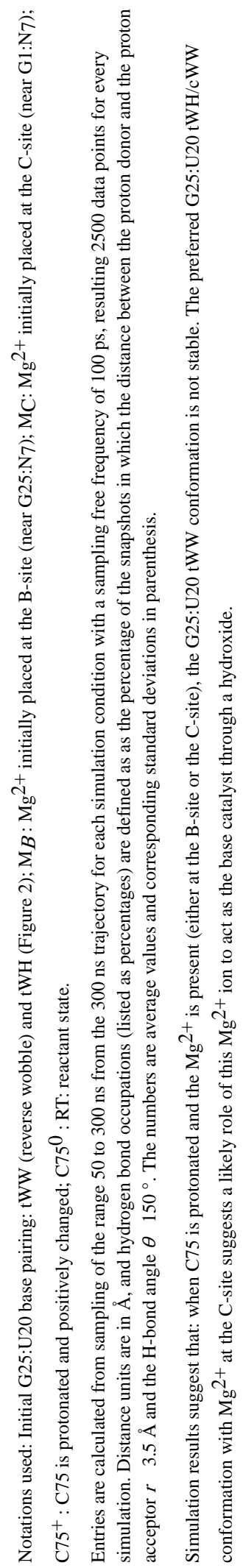




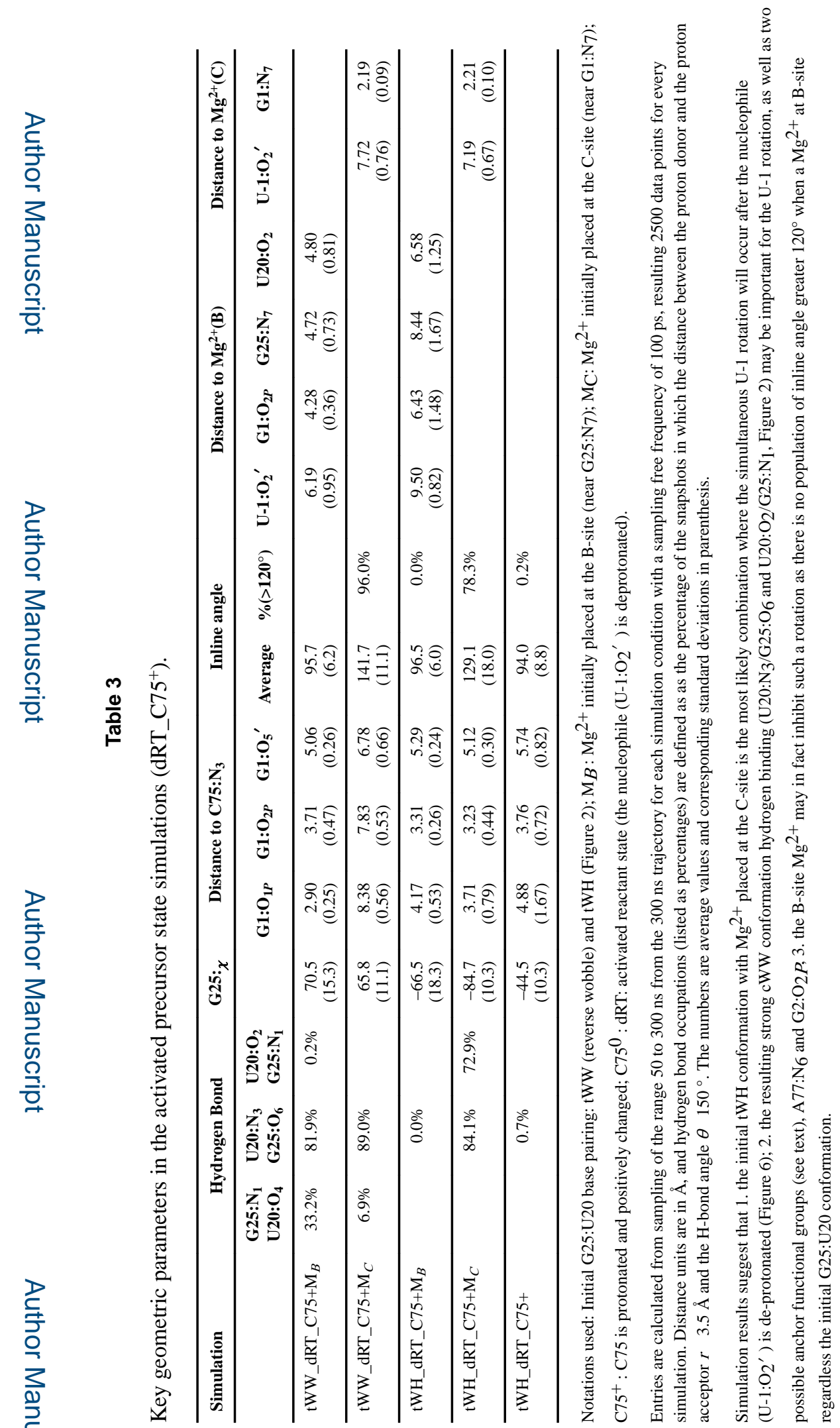


로을

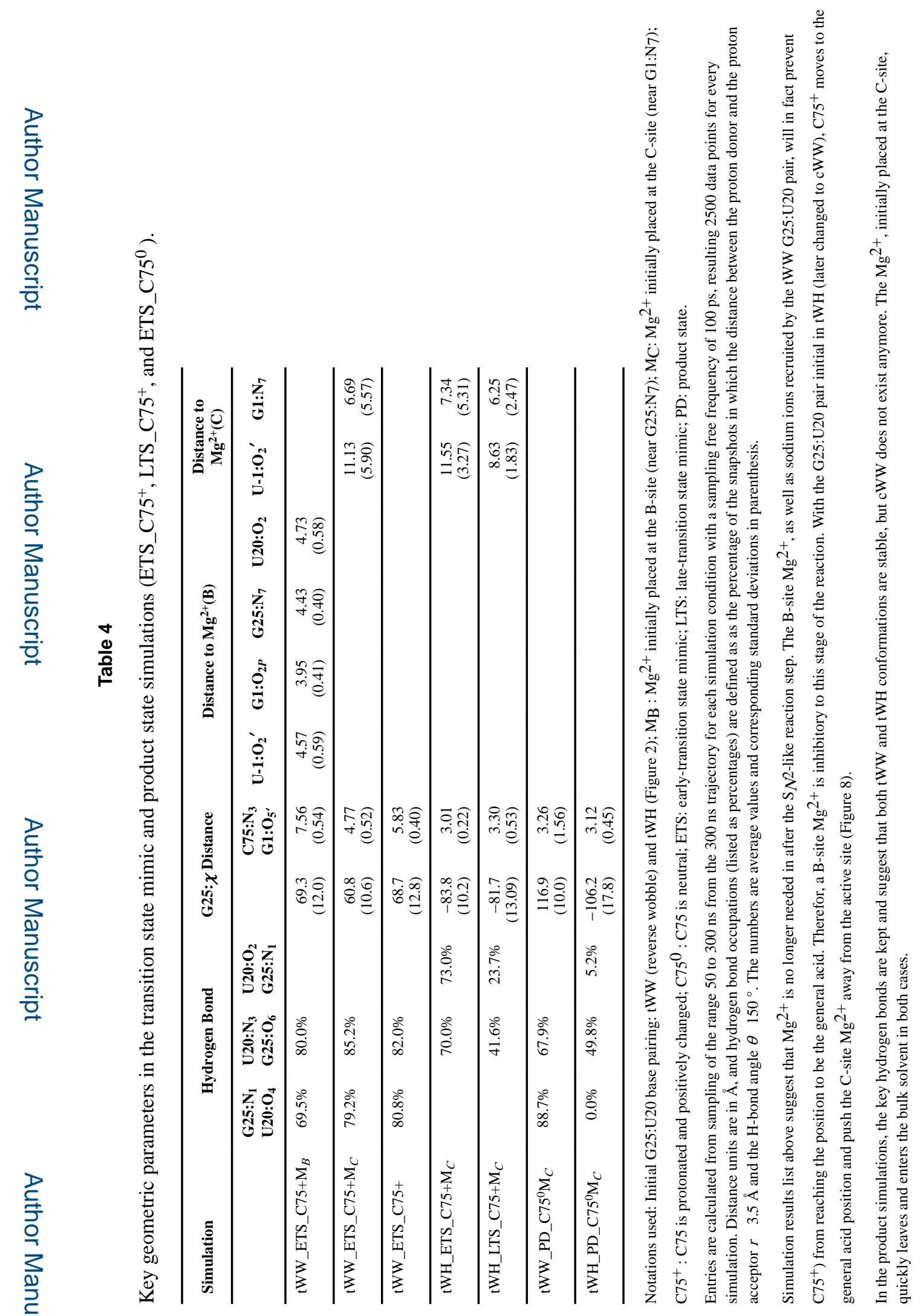




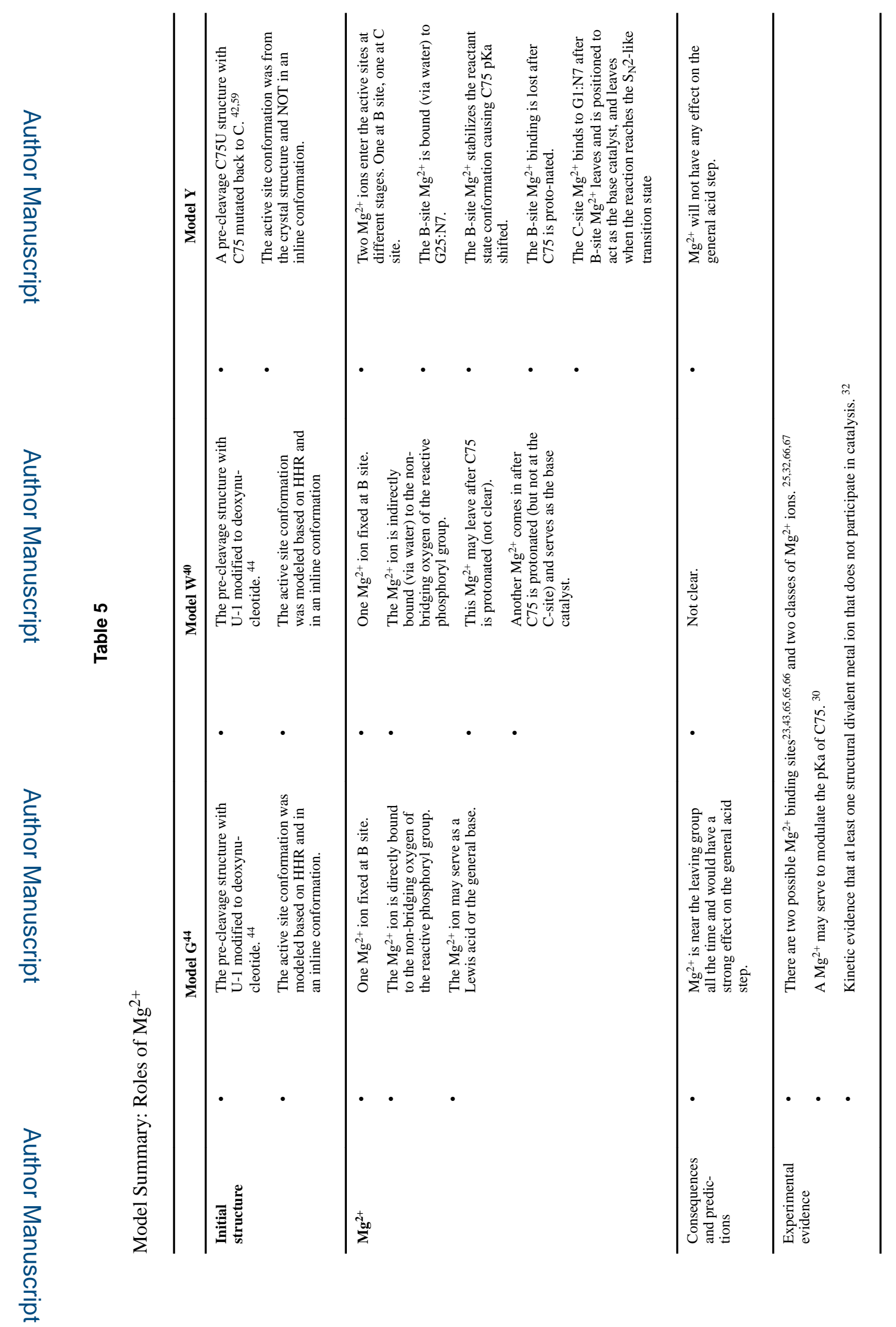

ACS Catal. Author manuscript; available in PMC 2016 October 20. 


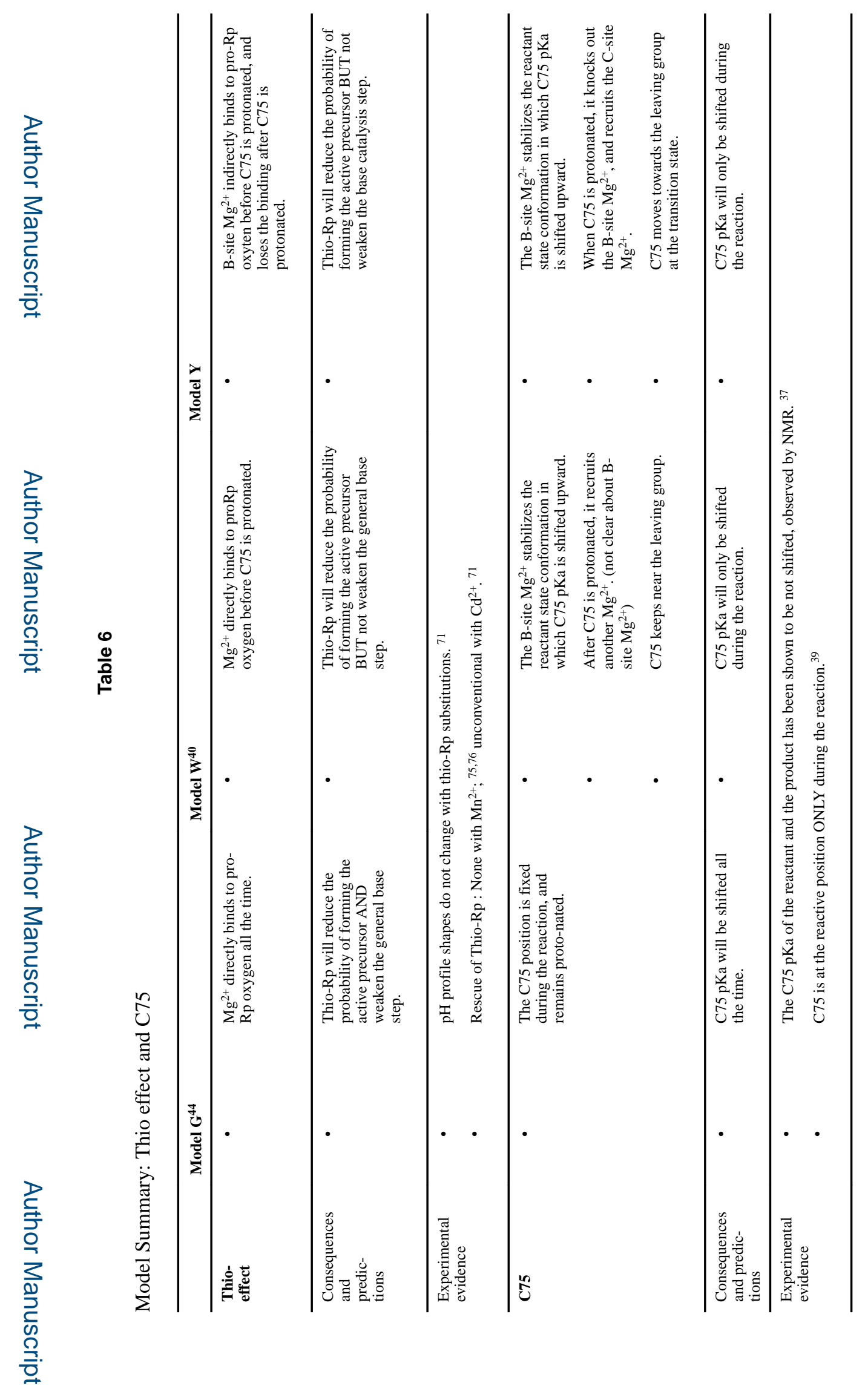

ACS Catal. Author manuscript; available in PMC 2016 October 20. 


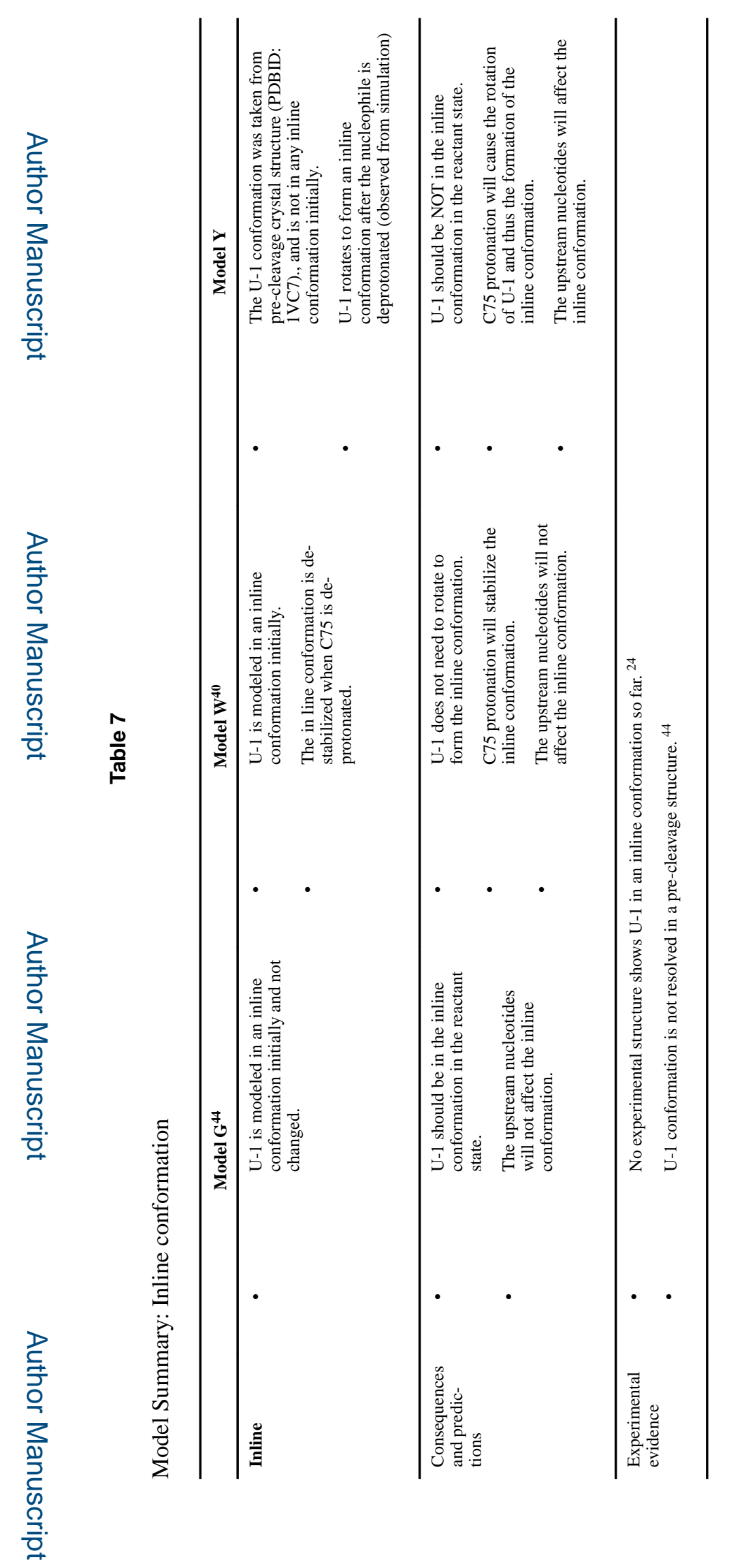

